\title{
Major Outcomes through Recent ROSA/LSTF Experiments and Future Plans
}

\author{
Takeshi Takeda, Yuki Wada, Yasuteru Sibamoto \\ Nuclear Safety Research Center, Japan Atomic Energy Agency, Ibaraki, Japan \\ Email: takeda.takeshi@jaea.go.jp
}

How to cite this paper: Takeda, T., Wada, Y. and Sibamoto, Y. (2021) Major Outcomes through Recent ROSA/LSTF Experiments and Future Plans. World Journal of Nuclear Science and Technology, 11, 17-42. https://doi.org/10.4236/wjnst.2021.111002

Received: November 25, 2020

Accepted: January 12, 2021

Published: January 15, 2021

Copyright $\odot 2021$ by author(s) and Scientific Research Publishing Inc. This work is licensed under the Creative Commons Attribution International License (CC BY 4.0).

http://creativecommons.org/licenses/by/4.0/

(c) (i) Open Access

\begin{abstract}
Many experiments have been conducted on accidents and transients of pressurized water reactor (PWR) employing the rig of safety assessment/largescale test facility (ROSA/LSTF). Recent research activities concerned with the OECD/NEA international joint projects included experimental investigation via the ROSA and ROSA-2 Projects, and counterpart testing with thermal-hydraulic integral test facilities under collaboration of the PKL-2, PKL-3, ATLAS, and ATLAS-2 Projects. Major results of the related integral effect tests (IETs) with the LSTF were reviewed to experimentally identify thermal-hydraulic phenomena involved, regarding the PWR accident sequences in accordance with the new regulatory requirements for the Japanese light-water nuclear power plants. Future separate effect test using the LSTF is planned to simulate loss of emergency core cooling system (ECCS) recirculation functions in a large-break loss-of-coolant accident (LOCA). Key results of the recent IETs utilizing the LSTF and future plans were presented relevant to multiple steam generator tube rupture accident with recovery operation, small-break LOCA with accident management measure on core exit temperature reliability, and small-break LOCA with thermal stratification under cold water injection from ECCS into cold legs. Also, main outcomes of the LSTF IETs were indicated for wide spectrum LOCA with core uncovery and anticipated transient without scram following small-break LOCA under totally failed high-pressure injection system.
\end{abstract}

\section{Keywords}

PWR, ROSA/LSTF, LOCA, ECCS, Integral Effect Test

\section{Introduction}

Japan Atomic Energy Agency has been operating the rig of safety assessment/ large-scale test facility (ROSA/LSTF) [1] [2] since 1985, triggered by the Three 
Mile Island Unit-2 reactor accident in 1979. The LSTF is a full-height and 1/48 volumetrically-scaled simulator with a two-loop system of a Westinghouse-type four-loop $3423 \mathrm{MW}$ (thermal) pressurized water reactor (PWR). There are other thermal-hydraulic integral test facilities currently in operation, such as PKL (volume scale of 1/145) in Germany [3], ATLAS (volume scale of 1/288) in Korea [4], PACTEL (volume scale of 1/305) in Finland [5], and ACME (volume scale of 1/94) in China [6].

Numerous experiments have been performed with the LSTF to investigate thermal-hydraulic behaviors of the PWR plant covering a wide spectrum of accidents and transients such as design basis accidents (DBAs) and beyond DBAs [7] [8] [9] [10] [11]. Table 1 summarizes the major design features of the LSTF to the reference PWR (Tsuruga Unit-2). The initial pressurizer (PZR) pressure is 15.5 MPa similar to the reference PWR. The highest core power, however, is 10 MW which is equal to $14 \%$ of the $1 / 48$-scaled PWR nominal core power. The LSTF experimental databases have been extensively used to evaluate the predictability of best estimate system analysis codes including ATHLET [12], TRACE [13], CATHARE [14], and RELAP5 [15] for the target thermal-hydraulic phenomena.

Recent efforts were pursued through the following OECD/NEA international collaborative projects. The ROSA and ROSA-2 Projects [16] [17] [18] [19] executed from April 2005 till September 2012 were aimed at dealing with topics of thermal-hydraulic reactor safety by making use of the LSTF at its full capabilities. In the framework of the ROSA-2 Project, mutual comparisons of blind calculations have indicated large scattering of calculated results and insufficient prediction accuracy of best estimate system analysis codes. Counterpart testing has been effected by exploiting thermal-hydraulic integral test facilities with different size

Table 1. Major design features of LSTF to reference PWR.

\begin{tabular}{ccc}
\hline Item & LSTF & Reference PWR \\
\hline Primary pressure (MPa) & 16 & 16 \\
Primary fluid temperature (K) & 598 & 598 \\
Core height (m) & 3.66 & 3.66 \\
Number of fuel rods & 1008 & 50,952 \\
Primary fluid volume (m $\left.{ }^{3}\right)$ & 8.14 & 347 \\
Total core power (MW) & 10 & 3423 (thermal) \\
Core inlet flow (ton/s) & 0.0488 & 16.7 \\
Number of primary loops & 2 & 4 \\
Hot leg inner diameter D (m) & 0.207 & 6.737 \\
Hot leg length L (m) & 3.69 & 8.14 \\
Hot leg L/D ${ }^{1 / 2}\left(\mathrm{~m}^{1 / 2}\right)$ & 8.11 & 3382 \\
Number of SG U-tubes & 141 & 20.2 \\
\hline Average length of SG U-tubes $(\mathrm{m})$ & 20.2 & \\
\hline
\end{tabular}


scaling and different structure shape at similar pressure regions under collaboration of the PKL-2, PKL-3, ATLAS, and ATLAS-2 Projects [20] [21] [22] [23] [24] [25] valuable for addressing scaling issues of phenomena and for upgrading techniques of scaling [26]. The resulting transient system responses were mostly consistent among the experimental facilities.

Meanwhile, the new regulatory requirements for the Japanese light-water nuclear power plants were enacted in 2013 [27]. Analytical studies have been carried out with some applicable computer codes to adequately account for the progression of PWR events for the evaluation of the effectiveness of measures against severe damage to the core according to the new regulatory requirements [28]. The following five accident sequences belong to beyond DBAs are involved in the PWR events that must be postulated in the new regulatory requirements; 1 ) station blackout (SBO), 2) loss of reactor shutdown functions, 3) loss of emergency core cooling system (ECCS) water injection functions, 4) loss of heat removal functions from secondary cooling water system, and 5) loss of ECCS recirculation functions.

In this study, foremost results of related integral effect tests (IETs) with the LSTF for the accident sequences of 1) through 4) were surveyed for experimentally specifying thermal-hydraulic phenomena concerned. Moreover, future plans were revealed for the accident sequences of 4) and 5) that need to be examined through IET or separate effect test (SET) with the LSTF. Chapter 2 describes the major assumptions and outcomes of the IETs, and the upcoming plans for the utilization of the LSTF. Table 2 shows the LSTF tests related to the new regulatory requirements and the major thermal-hydraulic phenomena identified.

PWR events involving specific thermal-hydraulic phenomena and transient responses, additionally, included 1) multiple steam generator tube rupture (MSGTR) accident with recovery operation, 2) small-break loss-of-coolant accident (LOCA) with accident management (AM) measure on core exit temperature

Table 2. LSTF tests relevant to the new regulatory requirements and major thermal-hydraulic phenomena identified.

\begin{tabular}{|c|c|c|c|c|}
\hline Item & Test ID & Test year & Test condition & Major thermal-hydraulic phenomena \\
\hline Station blackout (SBO) & TR-LF-16 & 2015 & $\begin{array}{l}\text { SBO transient with loss of } \\
\text { primary coolant with AM } \\
\text { measures }\end{array}$ & $\begin{array}{l}\text { Steam discharge through SG RVs, and single- and } \\
\text { two-phase natural circulation }\end{array}$ \\
\hline $\begin{array}{l}\text { Loss of reactor shutdown } \\
\text { functions }\end{array}$ & TR-LF-13 & 2007 & $\begin{array}{l}\text { LOFW transient without scram } \\
\text { with delayed actuation of AFW } \\
\text { system }\end{array}$ & Two-phase natural circulation \\
\hline $\begin{array}{l}\text { Loss of ECCS water } \\
\text { injection functions }\end{array}$ & SB-CL-41 & 2011 & $\begin{array}{l}\text { LOCA with } 8 \text {-in. break at cold } \\
\text { leg with AM measures under } \\
\text { totally failed HPI system }\end{array}$ & $\begin{array}{l}\text { Critical flow at break, steam discharge through SG RVs, } \\
\text { loop seal clearing, core boil-off, and steam condensation } \\
\text { on ACC water }\end{array}$ \\
\hline $\begin{array}{l}\text { Loss of heat removal } \\
\text { functions from secondary } \\
\text { cooling water system }\end{array}$ & TR-LF-07 & 1992 & $\begin{array}{l}\text { Total LOFW transient with } \\
\text { primary feed-and-bleed } \\
\text { operation }\end{array}$ & $\begin{array}{c}\text { Coolant discharge through PZR PORV, two-phase flow in } \\
\text { PZR, two-phase stratified flow in hot leg, and steam } \\
\text { condensation on ACC water }\end{array}$ \\
\hline $\begin{array}{l}\text { Loss of ECCS recirculation } \\
\text { functions }\end{array}$ & & & None & $\begin{array}{c}\text { Expected; steam binding, core liquid level reduction, and } \\
\text { core reflooding }\end{array}$ \\
\hline
\end{tabular}


(CET) reliability, 3) small-break LOCA with thermal stratification under cold water injection from ECCS into cold legs, 4) wide spectrum LOCA with core uncovery under total-failure of the high-pressure injection (HPI) system of ECCS, and 5) anticipated transient without scram (ATWS) following small-break LOCA under totally failed HPI system.

As for the first event, single steam generator tube rupture (SGTR) accident [29] is regarded as the containment bypass event. When the core damage happens in the MSGTR accident, coolant containing radioactive materials may be directly discharged to the environment. The second event concerns that thermocouples at the core exit are important instruments employed worldwide for starting some of AM actions by detecting elevated core temperatures [30]. The third event is a subject of investigation in terms of the structural integrity because thermal stratification is a matter of concern for pressurized thermal shock of pressure vessel [31] [32]. The fourth event involves a medium-break LOCA with fast core uncovery and a small-break LOCA with symptom-based AM measure with late core uncovery assuming that no HPI system is operated. The medium-break LOCA is associated with risk-informed regulation incorporating elucidation of occurrence frequency of incidents. The fifth event is positioned as a multiple fault accident with relatively high core power and continuous loss of the primary coolant that may bring about deterioration in core cooling.

With regard to the five PWR events mentioned above, in this study, the key conditions and results of the recent IETs using the LSTF were presented in Chapter 3. Also, the future plans were indicated for the events of 1) through 3) for improved understanding of the particular thermal-hydraulic phenomena and transient responses through IETs.

\section{PWR Accident Sequences for Evaluation of Effectiveness of Measures to Avoid Severe Core Damage}

\subsection{Station Blackout (SBO)}

\subsubsection{Outline of the Event}

As an AM measure, depressurization in the steam generator (SG) secondary-side system is made at a specified time after the SBO onset. Also, the auxiliary feedwater (AFW) is injected into the SG secondary-side activating the turbine-driven AFW pump shortly after the SBO inception. A test denoted as TR-LF-16 was among the series IETs on the SBO transient with loss of the primary coolant with the AM actions by use of the LSTF.

\subsubsection{Major Conditions of Relevant LSTF Test}

As shown in Table 2, the TR-LF-16 test simulated the SBO transient with 0.1\% break at a cold leg under total-failure of the HPI system of ECCS in 2015 [33]. Concerning the AM measures, fully opening of relief valves (RVs) in both SGs being injected the AFW into the secondary-side of both SGs was launched at time zero. The TR-LF-16 test was paid attention to the nitrogen gas flow into the primary system on the assumption of failed isolation of the accumulator (ACC) 
system of ECCS after the ACC system activation.

\subsubsection{Major Results of Relevant LSTF Test}

In the TR-LF-16 test, the primary pressure remained higher than the SG secondary-side pressure, as presented in Figure 1. Almost no nitrogen gas from the ACC tanks migrated to the SG U-tubes after fully opening a power-operated relief valve (PORV) of PZR. Single- and two-phase natural circulation resulted in continuous core cooling. No more IETs are planned for the SBO transient with loss of the primary coolant with the AM actions.

\subsection{Loss of Reactor Shutdown Functions}

\subsubsection{Outline of the Event}

ATWS induced by loss-of-feedwater (LOFW) is one of the events related to loss of reactor shutdown functions. The PZR PORV cyclic opening may continue to suppress the primary pressure increase. In procedures for the existing PWR, the AFW system starts up by operating the ATWS mitigation system soon after a scram signal is obtained. A test designated as TR-LF-13 was the only IET simulating the LOFW transient without scram by using the LSTF.

\subsubsection{Major Conditions of Relevant LSTF Test}

As indicated in Table 2, the scenario of the TR-LF-13 test was the LOFW transient without scram with delayed actuation of the AFW system under assumed total-failure of the HPI system in 2007 [34]. Based on the PWR calculation for the LOFW transient without scram with the RELAP5/MOD3 code, the core power reduced on account of negative reactivity feedback due to degradation of heat removal through the SGs, but was held at a specified high power thereafter (Figure 2). The SG secondary-side collapsed liquid level was kept at about 1/10 of the initial liquid level (i.e. about $1 / 20$ of the SG medium tube height) while replenishing with the AFW. The TR-LF-13 test was made giving attention to

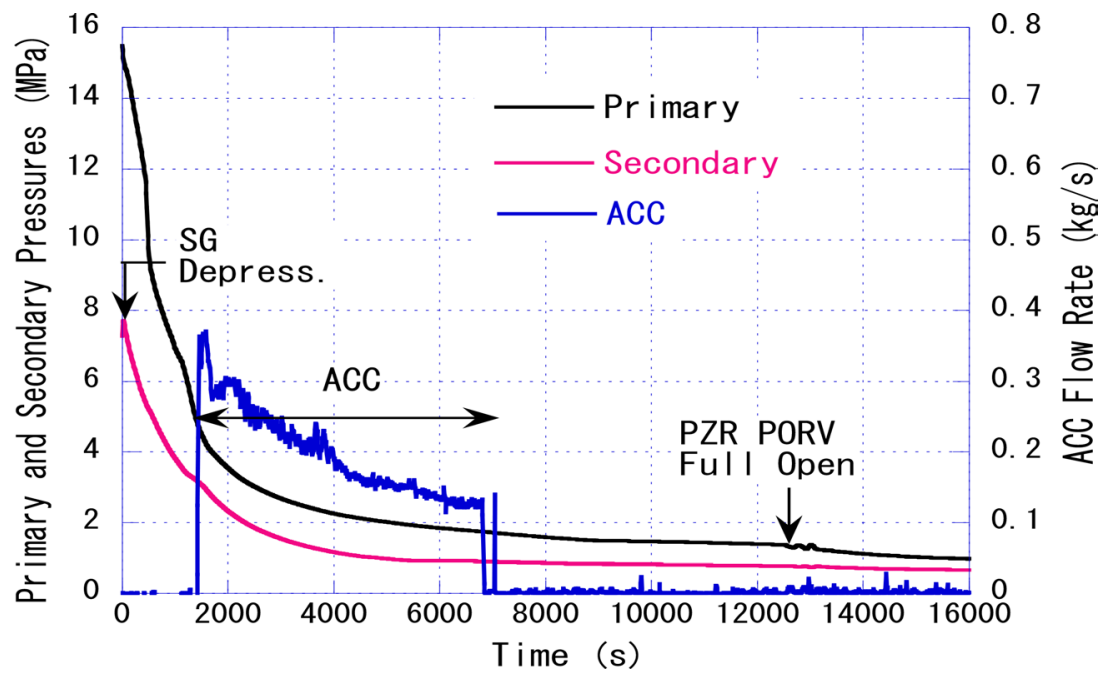

Figure 1. Primary and secondary pressures, and ACC flow rate in intact loop in TR-LF-16 test (SBO transient with loss of primary coolant with AM measures). 
time to the AFW system activation.

\subsubsection{Major Results of Relevant LSTF Test}

In the TR-LF-13 test, the PZR PORV cyclic opening prevented the overpressure of the primary system, as described in Figure 2. In parallel with the TR-LF-13 test, the PWR sensitivity analysis with the RELAP5/MOD3 code was carried out for the LOFW transient without scram under no actuation of the AFW system. As indicated in Figure 3, the core would be uncovered early owing to termination of two-phase natural circulation following the depletion of the SG secondary-side collapsed liquid level. The TR-LF-13 test and the sensitivity analysis

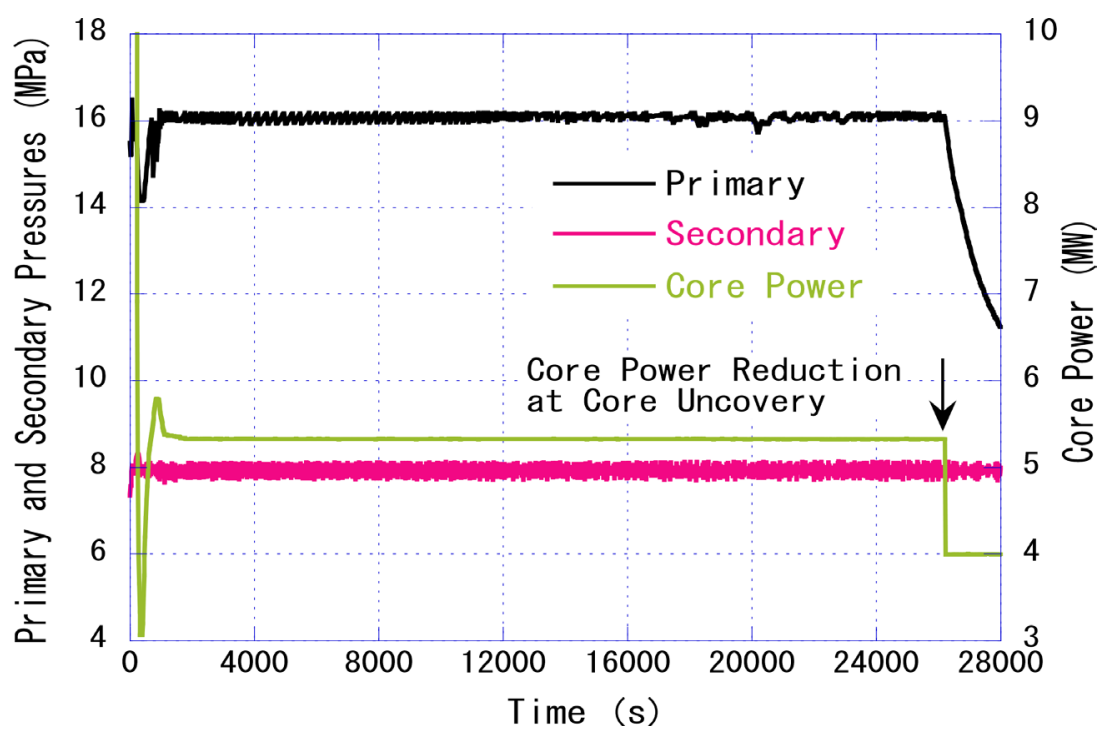

Figure 2. Primary and secondary pressures in loop with PZR, and core power in TR-LF13 test (LOFW transient without scram with delayed AFW actuation).

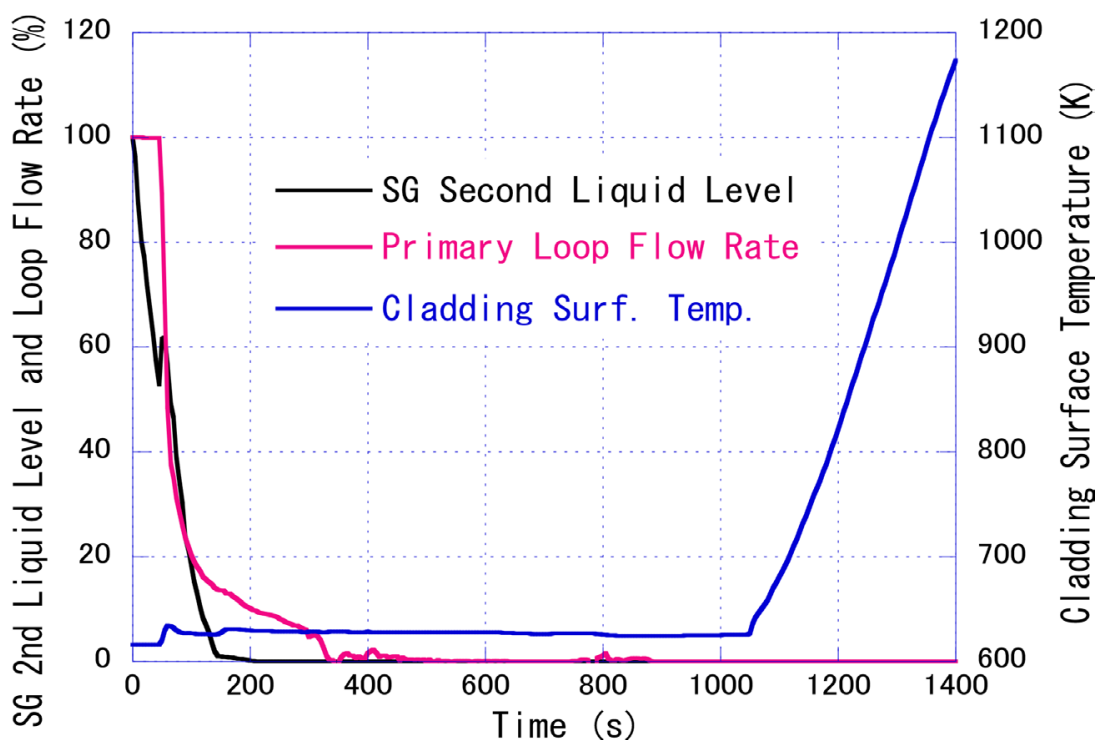

Figure 3. PWR calculated results for SG secondary-side liquid level, primary loop flow rate, and cladding surface temperature (LOFW transient without scram under no AFW actuation). 
revealed the importance of two-phase natural circulation by virtue of the AFW system operation from the viewpoint of cooling the core. There are no further IETs planned for the LOFW transient without scram.

\subsection{Loss of ECCS Water Injection Functions}

\subsubsection{Outline of the Event}

A medium- or small-break LOCA assuming total-failure of the HPI system is the event that represents loss of ECCS water injection functions [35]. Critical flow at the break controls the mass inventory of the primary coolant during the LOCA. AM measures are constituted of early SG secondary-side depressurization and early AFW system actuation. It is postulated that the core collapsed liquid level temporarily drops and then substantially decreases in this event. A test denoted as SB-CL-41 was among dozens of the IETs on the AM actions for the LOCA with totally failed HPI system by use of the LSTF.

\subsubsection{Major Conditions of Relevant LSTF Test}

As shown in Table 2, the SB-CL-41 test simulated a LOCA with 8-in. break at a cold leg under total-failure of the HPI system in 2011 [36]. Relating to the AM measure, the SG RVs were fully opened immediately after a safety injection (SI) signal was available at the PZR pressure of about $12 \mathrm{MPa}$. Also, the AFW injection was conducted into the SG secondary-side after several minutes since the SI signal generation.

\subsubsection{Major Results of Relevant LSTF Test}

In the SB-CL-41 test, loop seal clearing in both loops and core boil-off impacted the core collapsed liquid level, as presented in Figure 4. The SB-CL-41 test results showed that the phenomena postulated in this event are reproduced and the AM actions are effective in cooling the core because the ACC system actuation is

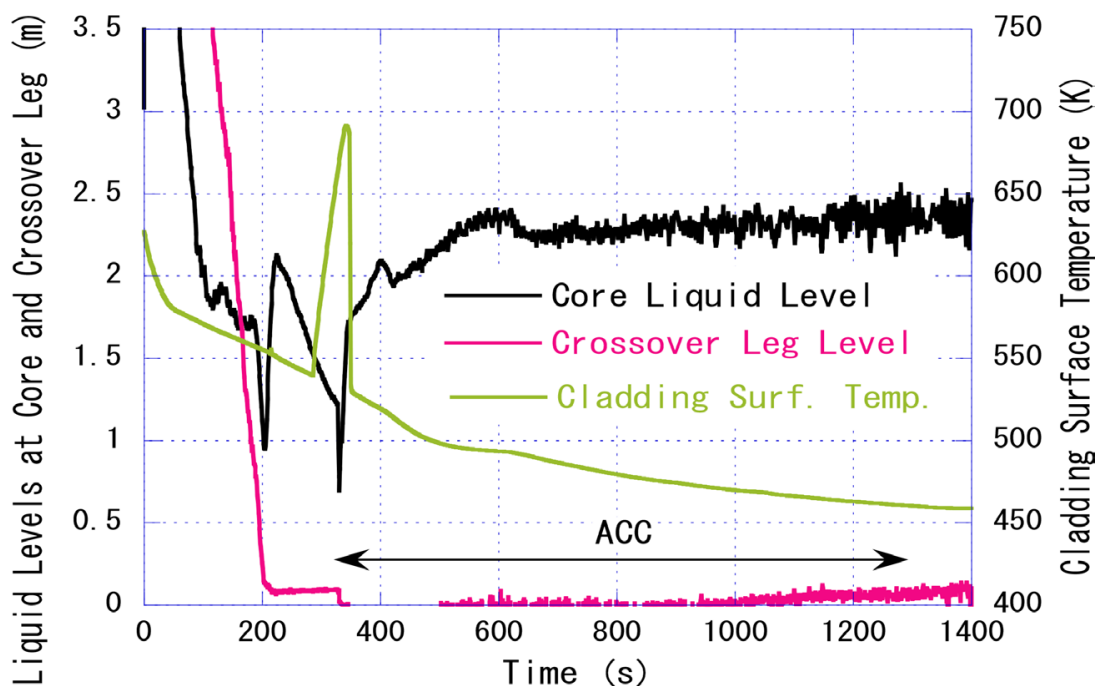

Figure 4. Collapsed liquid levels at core and crossover leg downflow-side, and cladding surface temperature in SB-CL-41 test (LOCA with 8-in. break at cold leg with AM measures under no HPI). 
made possible. Other related IETs revealed that a combination of break size and AM measure starting timing markedly affects peculiar phenomena such as loop seal clearing and core boil-off. No additional IETs are planned for the AM measures against the LOCA with total-failure of the HPI system.

\subsection{Loss of Heat Removal Functions from Secondary Cooling Water System}

\subsubsection{Outline of the Event}

Total LOFW transient is one of the events relevant to loss of heat removal functions from the secondary cooling water system in the abnormal transients during operation or the DBAs other than large- and medium-break LOCAs. A test designated as TR-LF-07 was the sole IET simulating the complete LOFW transient with the primary feed-and-bleed (F \& B) mode by using the LSTF.

\subsubsection{Major Conditions of Relevant LSTF Test}

As indicated in Table 2, the scenario of the TR-LF-07 test was the total LOFW transient in 1992 [37]. With regard to the primary F \& B operation, cold water was fed into a cold leg in a loop with PZR from the HPI system shortly after the SI signal was generated at a certain low level of the SG secondary-side. Meanwhile, the HPI water was supplied into a cold leg in a loop without PZR at a definite high pressure. The PZR PORV fully opening was performed after $30 \mathrm{mi}$ nutes since the SI signal generation.

\subsubsection{Major Results of Relevant LSTF Test}

In the TR-LF-07 test, an abrupt depression in the PZR liquid level by means of completely opening of the PZR PORV produced two-phase flow in the PZR and two-phase stratified flow in both hot legs, as depicted in Figure 5. Notable steam condensation on the ACC water in both cold legs brought the liquid level recovery

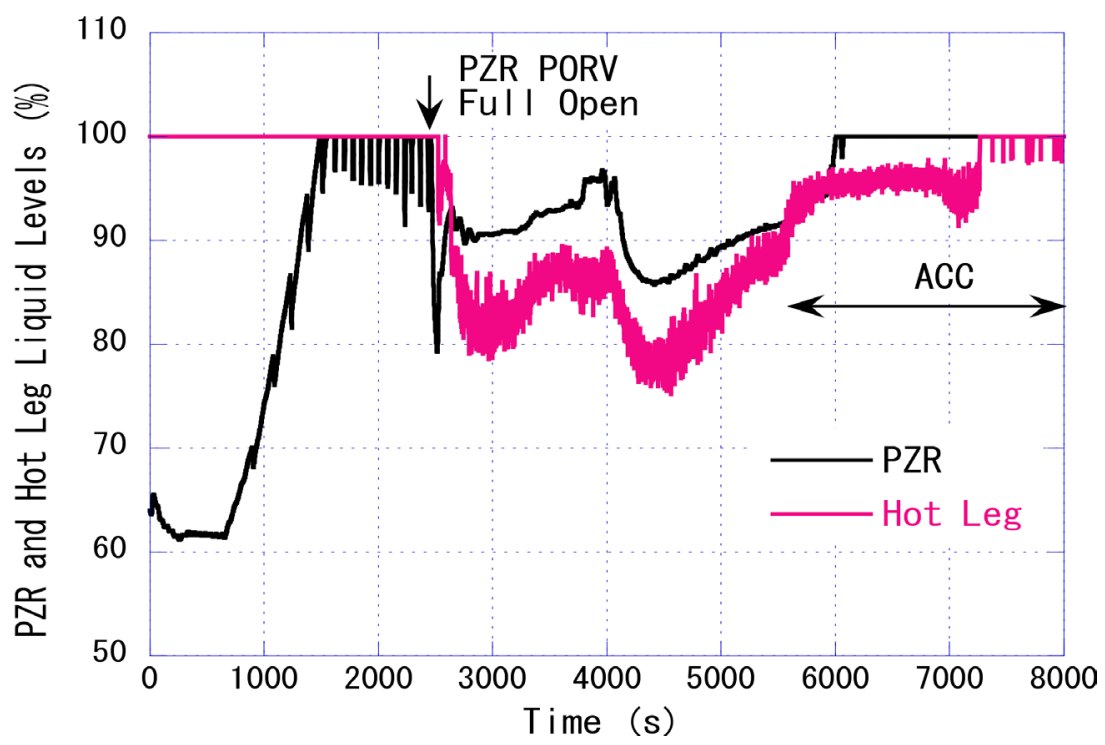

Figure 5. Liquid levels at PZR and hot leg in loop with PZR in TR-LF-07 test (total LOFW transient with primary feed-and-bleed operation). 
at the PZR and the hot leg. It will be needed to further verify the validity of the F $\&$ B procedure in the primary system through IET under the different F \& B operational condition.

\subsubsection{Future Plan}

In the future, IET will be conducted simulating the complete LOFW transient with the primary F \& B mode. The IET objectives are to examine the effects of experimental parameters (HPI flow rate, time to the PZR PORV fully opening, etc.) on primary depressurization and core cooling. The HPI system is expected to be single-failure, unlike the TR-LF-07 test. The starting timing of the PZR PORV completely opening is going to be decided on the basis of the depletion of the SG secondary-side collapsed liquid level. This means that the PZR PORV fully opening will be initiated later than in the TR-LF-07 test. The late PZR PORV completely opening may be a more severe condition in terms of cooling and depressurizing the primary system.

\subsection{Loss of ECCS Recirculation Functions}

\subsubsection{Outline of the Event}

Loss of ECCS recirculation functions is represented by loss of both high-pressure and low-pressure recirculation functions in a large-break LOCA. The primary pressure rapidly lowers to near-atmospheric pressure after the break owing to large break flow rate. The SG secondary-side collapsed liquid level remains at a certain high liquid level. Cold water is injected from ECCS into both cold legs shortly after the break. Liquid droplets evaporate in the SG U-tubes on account of the backflow of water from the SG secondary-side which contains a hot fluid. The pressure drop increase in the SG U-tubes is ascribed to the steam production. This steam binding phenomenon [38] [39] [40] may bring about a decrease in the core collapsed liquid level and a rise in the cladding surface temperature. After ECCS water sources deplete, failure of switching the water sources for the ECCS recirculation causes to stop the ECCS water injection. As for an alternative method to the ECCS recirculation features, water is fed into the cold leg via the containment recirculation sump by operating the spray pump for the containment (as illustrated in Figure 6) at a specified time after the ECCS water injection completion. The feedwater into the cold leg may assist in core reflooding. There, however, have been no LSTF tests for loss of ECCS recirculation functions.

\subsubsection{Future Plan}

In the future, SET will be undertaken at near-atmospheric pressure to reproduce the expected phenomena, in relation to the loss of ECCS recirculation functions in the large-break LOCA (Table 2). In the SET, ECCS is restarted instead of resuming water injection taking advantage of the containment spray pump. The SET conditions include the core power, the primary and SG secondary-side pressures, the liquid level in the pressure vessel, the timings of start, stop, and 


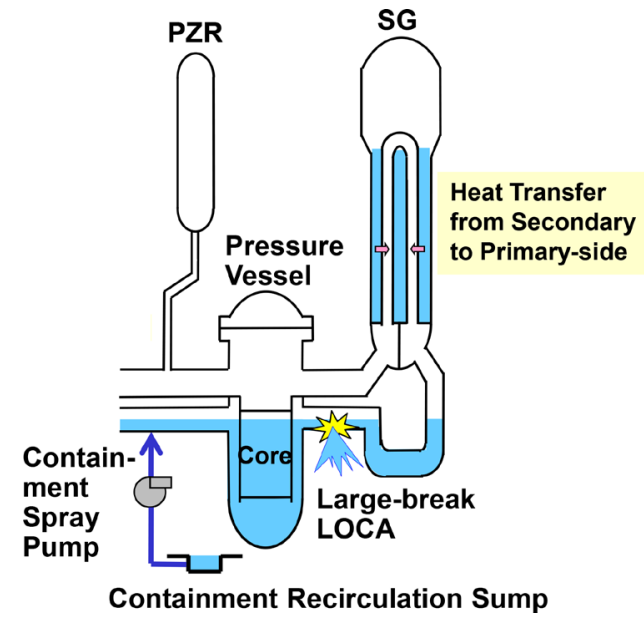

Figure 6. PWR coolant distribution during loss of ECCS recirculation functions.

restart of ECCS, as well as the flow rate of ECCS. The SET conditions are also going to be defined based on the calculation for a large-break LOCA of PWR through the utilization of the RELAP5/MOD3 code. There are such calculation parameters as discharge coefficient at the break and ECCS operational conditions. The PWR calculation is intended to provide such information as the collapsed liquid levels at the core and the vessel downcomer, and the cladding surface temperature. The SET procedures for the test conditions will be referred to those for the previous LSTF SET simulating the reflood phase of large-break LOCA [41].

\section{PWR Events Involving Specific Thermal-Hydraulic Phenomena and Transient Responses}

\subsection{Multiple Steam Generator Tube Rupture (MSGTR) Accident with Recovery Operation}

\subsubsection{Outline of the Event}

The occurrence probability of an accident arisen from MSGTR is very low. The MSGTR accident, however, is categorized in accident sequences which directly linked to the core damage in the seismic probabilistic risk assessment of level-1 [42] [43]. Recovery action against the MSGTR accident includes fully opening of the intact SG RV, completely opening of the PZR PORV, and the HPI water injection into both cold legs. Recent attempts were pursued to clarify the effectivity of the recovery operation from the MSGTR accident for core cooling by a series of the LSTF IETs.

\subsubsection{Major Conditions of Relevant LSTF Tests}

Three IETs denoted as SB-SG-16, SB-SG-17, and SB-SG-18 were implemented on the recovery operation against the MSGTR accident in 2017, 2018, and 2019 respectively, as shown in Table 3. The following two assumptions are the common test conditions. Break size was equivalent to a double-ended guillotine break of the 1/48-scaled cross-sectional area of six of SG U-tubes in the reference 
Table 3. Major conditions of three LSTF IETs on MSGTR accident with recovery operation.

\begin{tabular}{|c|c|c|c|}
\hline \multirow{2}{*}{ Item } & \multicolumn{3}{|c|}{ Condition } \\
\hline & SB-SG-16 & SB-SG-17 & SB-SG-18 \\
\hline Break valve open & \multicolumn{3}{|c|}{ Time zero } \\
\hline Generation of scram signal & \multicolumn{3}{|c|}{$\mathrm{PZR}$ pressure $=12.97 \mathrm{MPa}$} \\
\hline Generation of SI signal & \multicolumn{3}{|c|}{$\mathrm{PZR}$ pressure $=12.27 \mathrm{MPa}$} \\
\hline Start of HPI system & None & Soon after SI signal generation & None \\
\hline Start of intact SG depressurization & \multicolumn{3}{|c|}{12 minutes after scram signal generation } \\
\hline Auxiliary feedwater system & \multicolumn{2}{|r|}{ Actuation } & Total-failure \\
\hline Start of primary depressurization & $\begin{array}{l}\text { Primary pressure }=\text { broken SG } \\
\text { secondary-side pressure }\end{array}$ & $\begin{array}{l}\text { Hot leg fluid temperature in intact loop }= \\
\qquad 547 \mathrm{~K}\end{array}$ & $\begin{array}{l}\text { Primary pressure }=\text { broken } \\
\text { SG secondary-side pressure }\end{array}$ \\
\hline End of HPI system & None & PZR liquid level = $1 \mathrm{~m}$ & None \\
\hline End of primary depressurization & End of test & $\begin{array}{c}\text { Confirmation of effect of primary } \\
\text { depressurization }\end{array}$ & End of test \\
\hline End of intact SG depressurization & End of test & $\begin{array}{l}\text { Primary pressure }=\text { broken SG } \\
\text { secondary-side pressure }\end{array}$ & End of test \\
\hline Start of ACC system & \multicolumn{2}{|c|}{ Primary pressure $=4.51 \mathrm{MPa}$} & Total-failure \\
\hline $\begin{array}{l}\text { Start of manual coolant injection } \\
\text { from HPI system into cold legs }\end{array}$ & \multicolumn{2}{|r|}{ None } & $\begin{array}{l}\text { Maximum core exit } \\
\text { temperature }=623 \mathrm{~K}\end{array}$ \\
\hline $\begin{array}{l}\text { End of manual coolant injection } \\
\text { from HPI system into cold legs }\end{array}$ & \multicolumn{2}{|r|}{ None } & End of test \\
\hline
\end{tabular}

PWR. The intact SG RV was fully opened after 12 minutes since the PZR pressure decreased to $12.97 \mathrm{MPa}$, similar to the single SGTR accident test [19].

The SB-SG-16 test assumption was total-failure of the HPI system. The SBSG-17 test was supposed to be single-failure of the HPI system that injected cold water into both cold legs. The HPI water injection was started soon after the PZR pressure dropped to $12.27 \mathrm{MPa}$, while it was ended when the PZR liquid level attained $1 \mathrm{~m}$ following the PORV fully opening [19]. As the SB-SG-18 test conditions, by contrast, the HPI, ACC, and AFW systems were completely failed.

\subsubsection{Major Results of Relevant LSTF Tests}

Table 4 shows the chronology of the major events of three IETs on the MSGTR accident with the recovery operation. In the SB-SG-16 test, the primary pressure was equalized to the broken SG secondary-side pressure even after the intact SG RV fully opening started. The primary depressurization via the PZR PORV completely opening resulted in the activation of the ACC system at the primary pressure of $4.51 \mathrm{MPa}$. In the SB-SG-17 test, thermal stratification was seen in a cold leg in broken loop under the HPI water injection as a result of little circulation flow rate in broken loop. By contrast, natural circulation remarkably dominated in intact loop, which gave rise to no thermal stratification. The intact SG depressurization was terminated a little after the primary pressure became equal 
Table 4. Chronology of major events of three LSTF IETs on MSGTR accident with recovery operation.

\begin{tabular}{|c|c|c|c|c|}
\hline \multirow{2}{*}{ Event } & \multicolumn{4}{|c|}{ Time (s) } \\
\hline & SB-SG-16 & SB-SG-17 & & SB-SG-18 \\
\hline Break valve open & & 0 & & \\
\hline Generation of scram signal & 72 & 68 & & 72 \\
\hline Generation of SI signal & 110 & 118 & & 112 \\
\hline Start of HPI system & None & 128 & & None \\
\hline Start of intact SG depressurization & 800 & 791 & & 792 \\
\hline Start of primary depressurization & 1400 & 2039 & & 1400 \\
\hline End of HPI system & None & 2075 & & None \\
\hline End of primary depressurization & 7300 & 2680 & & 6100 \\
\hline End of intact SG depressurization & 7300 & 3706 & & 6100 \\
\hline Start of ACC system & 3250 & & None & \\
\hline End of ACC system & 6760 & & None & \\
\hline $\begin{array}{l}\text { Start of manual coolant injection } \\
\text { from HPI system into cold legs }\end{array}$ & & & & 5157 \\
\hline $\begin{array}{l}\text { End of manual coolant injection } \\
\text { from HPI system into cold legs }\end{array}$ & & & & 6030 \\
\hline
\end{tabular}

to the broken SG secondary-side pressure due to the completion of the PZR PORV fully opening, which led to no actuation of the ACC system.

In the SB-SG-18 test, the PZR PORV completely opening was effective on the primary depressurization until the SG secondary-side collapsed liquid level became close to zero. Heat removal through the SGs was lost afterwards because the SG secondary-side was emptied of liquid on the grounds of unavailability of the AFW system, which brought core uncovering. Cold water was manually fed further from the HPI system into both cold legs at a specified flow rate when the maximum CET rose to $623 \mathrm{~K}$. The manual HPI water injection caused the peak cladding temperature (PCT) of $802 \mathrm{~K}$ and the whole core quenching. The SBSG-18 test results suggest that the core would be uncovered in the MSGTR accident with completely failed ECCS and AFW system.

The SB-SG-16, SB-SG-17, and SB-SG-18 tests revealed that the recovery action contributes to core cooling effectively. Meanwhile, a test designated as SB-SG-14 was performed in 2010, simulating the single SGTR accident that initiated simultaneously with a main steam line break (MSLB) being coupled with operation of the HPI system [19]. There, however, have not been any LSTF IETs concerning the MSGTR accident with the MSLB.

\subsubsection{Future Plan}

In the future, IETs will be carried out simulating the MSGTR accident that induced by the MSLB in combination with the recovery operation. The IET purposes are to make clear the influences of test parameters (break sizes for the 
MSGTR and MSLB, time to the MSGTR, etc.) on primary depressurization, thermal stratification, and core cooling. The break sizes for the MSGTR and MSLB are going to be referred to those for the LSTF IETs simulating the MSGTR accident and the MSLB accident [44] respectively, unlike the SB-SG-14 test. In the MSLB accident test in 1990, the MSLB break size was equal to $12 \%$ of the $1 / 48$-scaled cross-sectional area of one SG main steam tube of the reference PWR. The starting timing of the MSGTR will be determined based on the depletion of the SG secondary-side collapsed liquid level following the MSLB, unlike the SB-SG-14 test. The HPI flow rate will be reduced in a stepwise procedure.

\subsection{Small-Break LOCA with Accident Management (AM) Measure on Core Exit Temperature (CET) Reliability}

\subsubsection{Outline of the Event}

A substantial increase in the cladding surface temperature launches well before the core exit thermocouples indicate superheating during a small-break LOCA. Experimental data have been provided with some of the LSTF IETs regarding the AM measures on the basis of the CET response during the small-break LOCA. In the LSTF IETs, however, the AM actions were undertaken at the maximum CET of $623 \mathrm{~K}$.

\subsubsection{Major Conditions of Relevant LSTF Tests}

Three IETs denoted as SB-PV-07, SB-PV-09, and SB-HL-18 were made on the small-break LOCA under assumed total-failure of the HPI system. The vessel upper head break sizes were $1 \%$ and $1.9 \%$ for the SB-PV-07 test [45] and the SB-PV-09 test [18] respectively in 2005. The SB-PV-07 test was also dedicated to the ATLAS-2 Project as a preferable counterpart exercise. The break location and size respectively for the SB-HL-18 test in 2011 were hot leg and $1.5 \%$, while low-pressure phase of the SB-HL-18 test was defined as a counterpart to the PKL-2 Project test [23]. Manually injection of cold water into both cold legs at a certain flow rate utilizing the HPI system was adopted as the AM measure for the SB-PV-07 test. By contrast, the SG RVs fully opening was taken accompanying by the AFW injected into the SG secondary-side for the SB-PV-09 and SB-HL-18 (low-pressure phase) tests.

\subsubsection{Major Results of Relevant LSTF Tests}

Figures 7-9 show the CETs versus cladding surface temperatures in the SB-PV07, SB-PV-09, and SB-HL-18 (low-pressure phase) tests, respectively. Positions 9,8 , and 7 respectively are situated at levels of about $1 / 1,5 / 6$, and $7 / 10$ of the active core height. In the SB-PV-09 test, the core power was automatically lowered to a certain low level because the maximum cladding surface temperature became above the criterion of $958 \mathrm{~K}$, which affected the PCT greatly. The peak CETs observed at around the center of the upper core plate were $713 \mathrm{~K}, 748 \mathrm{~K}$, and $662 \mathrm{~K}$ respectively in the SB-PV-07, SB-PV-09, and SB-HL-18 (low-pressure phase) tests, while the PCTs seen at Position 7 were $881 \mathrm{~K}, 975 \mathrm{~K}$, and $822 \mathrm{~K}$. 


\subsubsection{Future Plan}

Further investigation is required to better understand the CET reliability by means of IET on the AM measures based on the CET performance for the small-break LOCA assuming that the HPI system is totally failed. The IET objectives are to account for the relation between the CET and the cladding surface temperature under the distinct break and AM conditions, which may cover the higher temperature ranges compared to the previously related IETs with the LSTF. The integrity of electrically heated rods should be guaranteed up to 1073 $\mathrm{K}$ at a definite low level of core power as a typical decay heat, built on nonconsolidated performance test of the heated rods. The PCT is expected to be above 975 $\mathrm{K}$ without an automatic core power drop to a fixed low level. For that purpose,

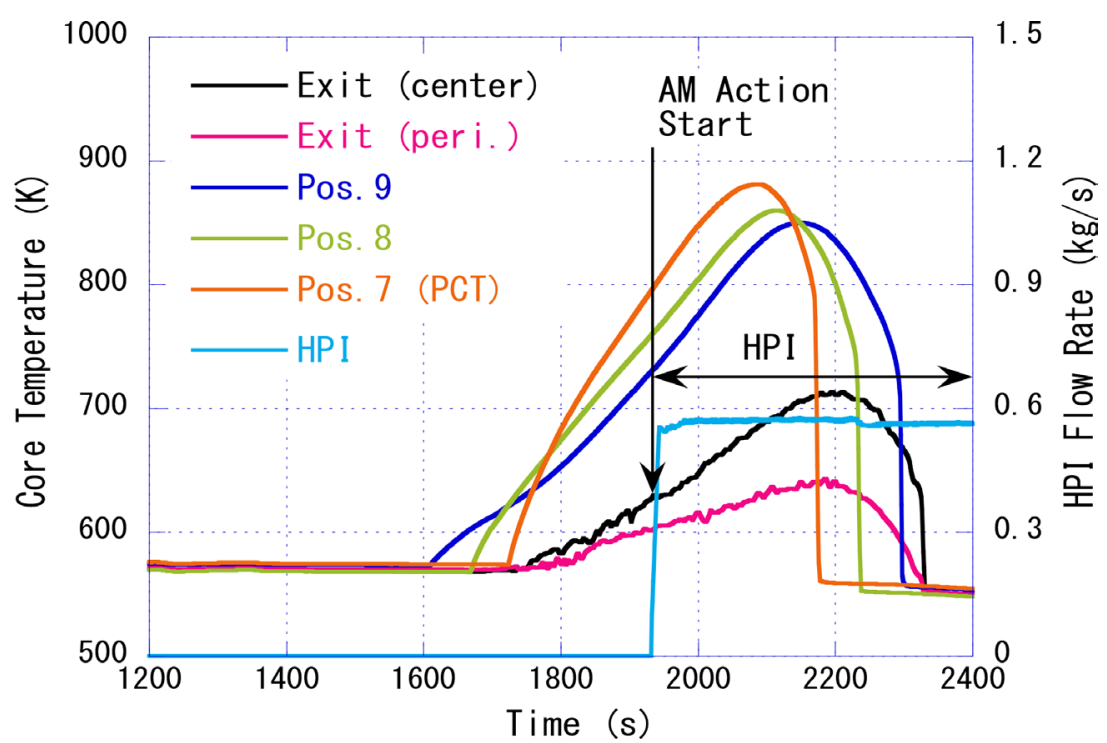

Figure 7. Core exit temperatures versus cladding surface temperatures in SB-PV-07 test (LOCA with $1 \%$ break at vessel upper head with AM measures).

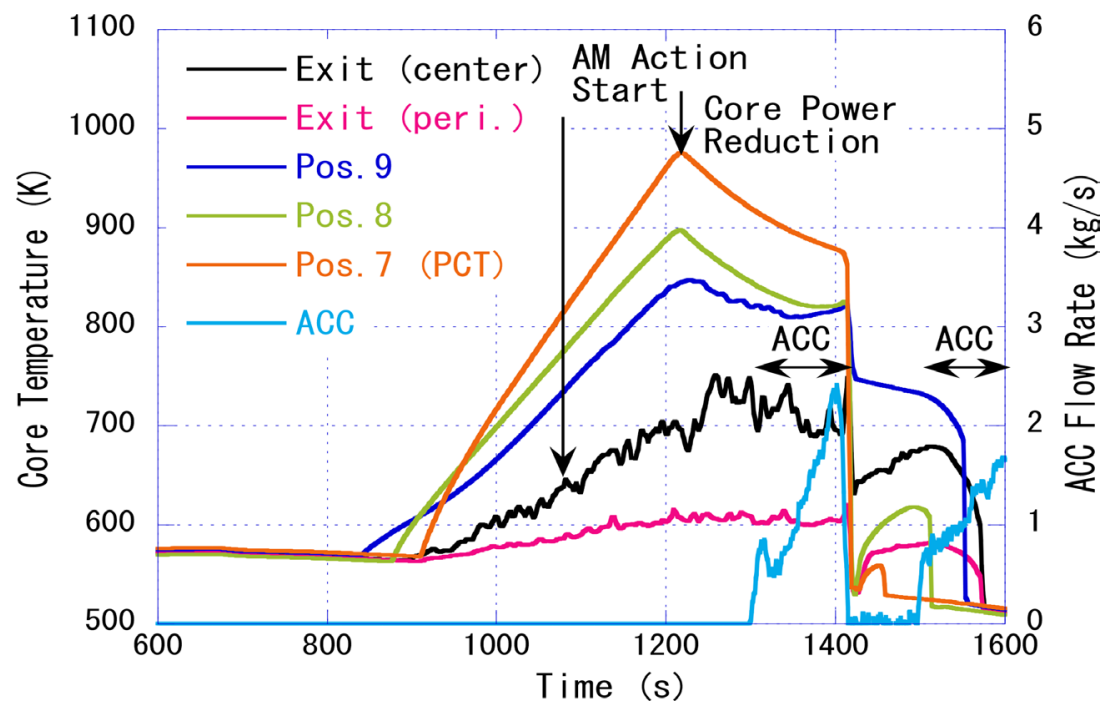

Figure 8. Core exit temperatures versus cladding surface temperatures in SB-PV-09 test (LOCA with $1.9 \%$ break at vessel upper head with AM measures). 


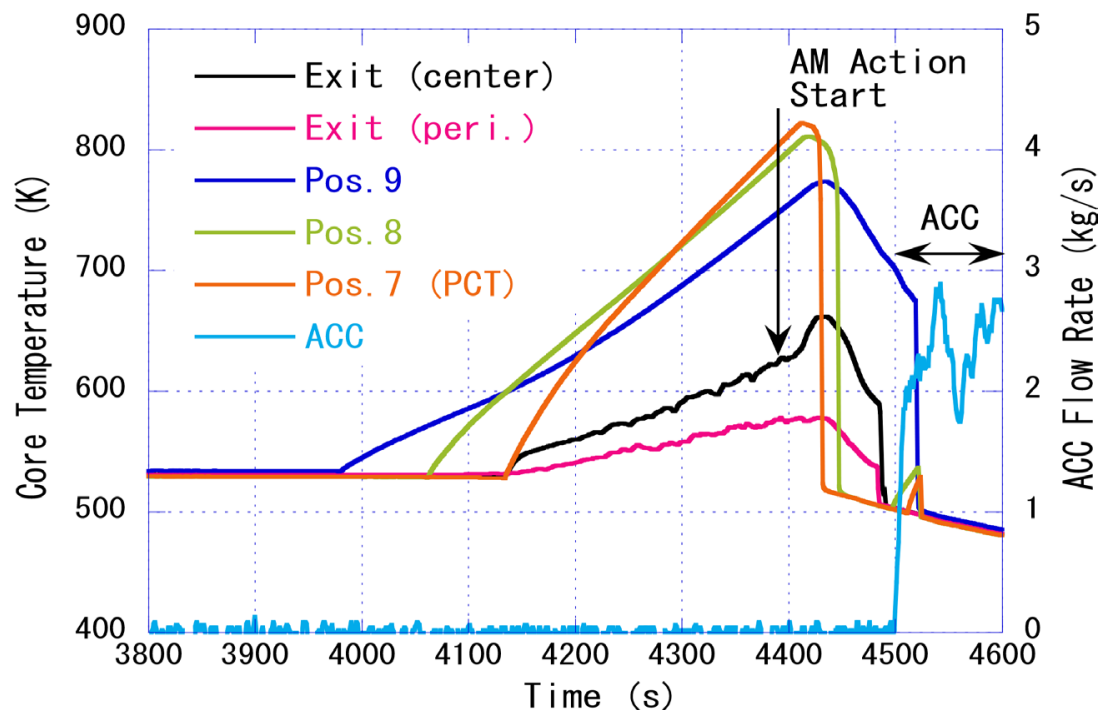

Figure 9. Core exit temperatures versus cladding surface temperatures in SB-HL-18 (lowpressure phase) test (LOCA with $1.5 \%$ break at hot leg with AM measures).

the AM actions will be taken when the maximum CET is well above $623 \mathrm{~K}$, while predefining an appropriate criterion of the maximum cladding surface temperature. The AM measures, the break location and size will be established referring to those for the relevant LSTF IETs.

\subsection{Small-Break LOCA with Thermal Stratification under Cold Water Injection from ECCS into Cold Legs}

\subsubsection{Outline of the Event}

When ECCS is under operation, cold water is fed into both cold legs and migrates to the pressure vessel through vessel downcomer. Thermal stratification attributed to inadequate cold and hot coolant mixing was seen in the LSTF IETs simulating the MSLB accident [44] or the single SGTR accident with the MSLB [19]. A test designated as SB-HL-17 was the only IET concerning the small-break LOCA focusing on thermal stratification under cold water injection from ECCS by use of the LSTF.

\subsubsection{Major Conditions of Relevant LSTF Test}

The SB-HL-17 test simulated a LOCA with $1 \%$ break at a hot leg under assumed single-failure of the HPI system that injected cold water into both cold legs in 2007 [46]. Cold water was supplied into both cold legs employing the HPI system soon after the PZR pressure lowered to 12.27 MPa.

\subsubsection{Major Results of Relevant LSTF Test}

In the SB-HL-17 test, the SG secondary-side pressure fluctuated through cyclic opening of the SG RVs being followed by the primary pressure fluctuation, as indicated in Figure 10. After around $1000 \mathrm{~s}$, a large decrease started in the primary pressure under the influence of the break flow rate. Figure 11 and Figure 12 show the fluid temperatures at cold legs in intact loop and broken loop, re- 
spectively. Thermal stratification was observed in both cold legs during the time periods of cold water injection from the HPI and ACC systems by reason of almost no circulation flow rate in both loops. The maximum difference in the vertical cold leg fluid temperatures was about $135 \mathrm{~K}$ at around $2785 \mathrm{~s}$ in intact loop, whereas it was about $110 \mathrm{~K}$ at around $2740 \mathrm{~s}$ in broken loop. The cold leg fluid temperature difference between the two loops may be subject to the influence of different angles of the ECCS injection line to the cold leg; $90^{\circ}$ or $45^{\circ}$. Decrease rates of the primary pressure and the cold leg fluid temperature were dependent on the ACC flow rate.

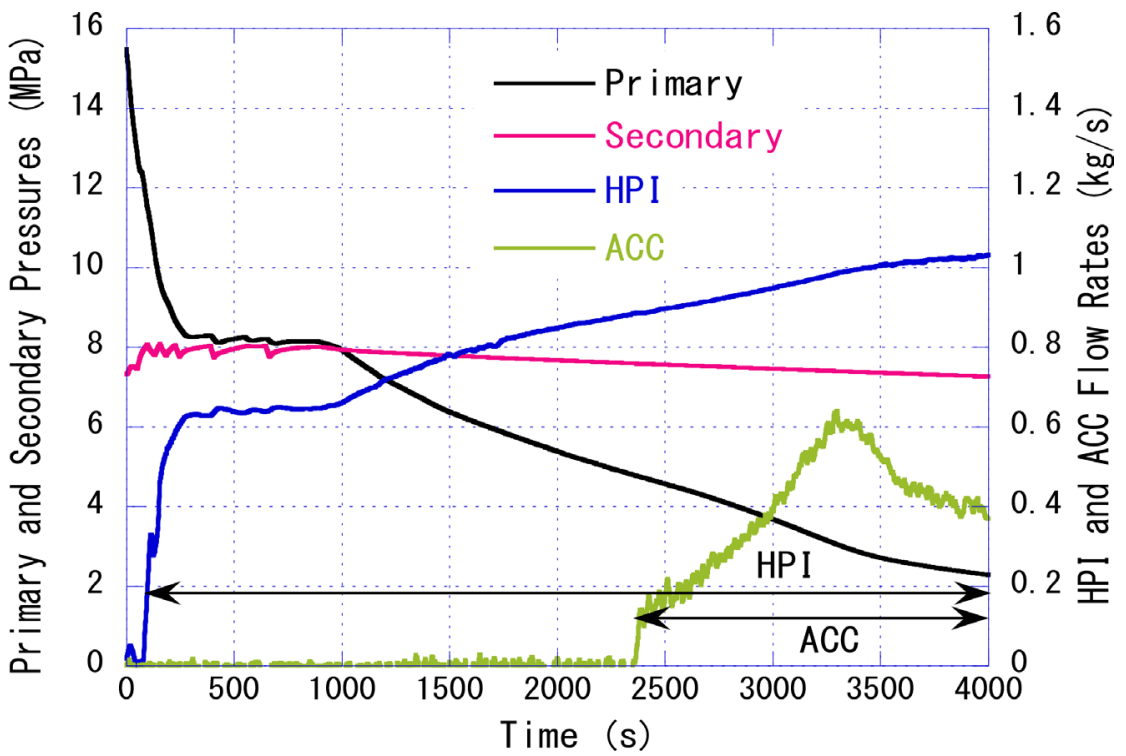

Figure 10. Primary and secondary pressures, HPI and ACC flow rates in intact loop in SB-HL-17 test (LOCA with $1 \%$ break at hot leg under single failure of HPI).

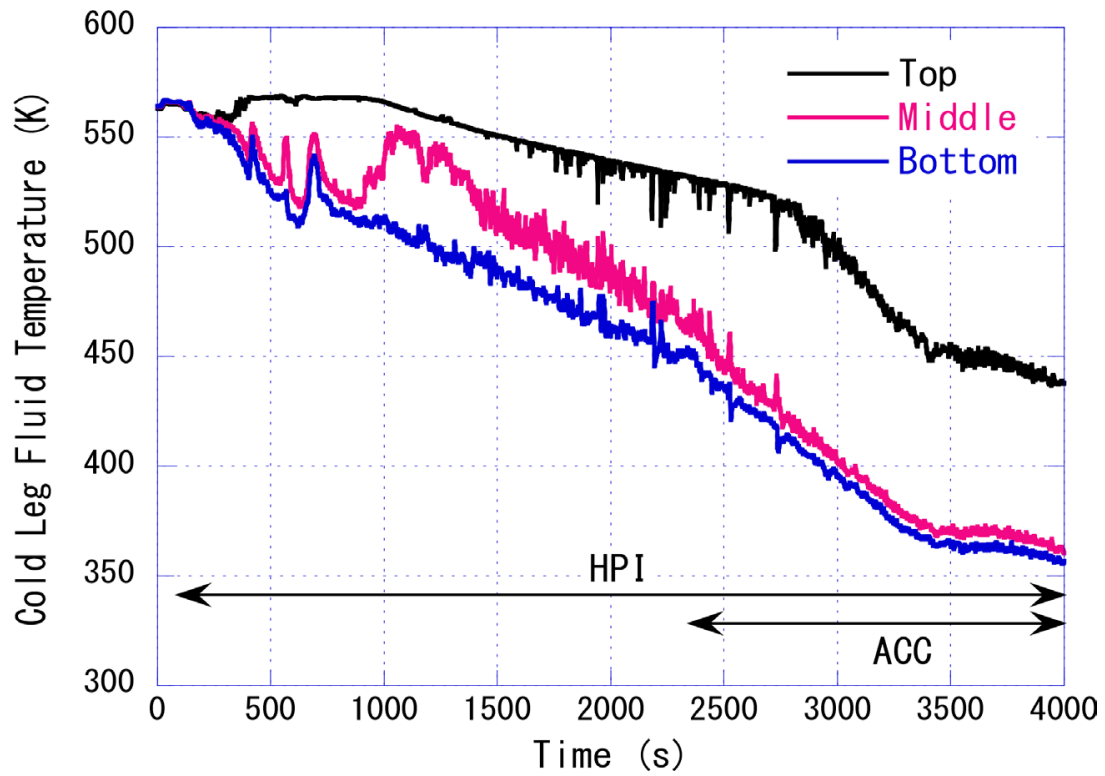

Figure 11. Cold leg fluid temperature in intact loop in SB-HL-17 test (LOCA with 1\% break at hot leg under single failure of HPI). 


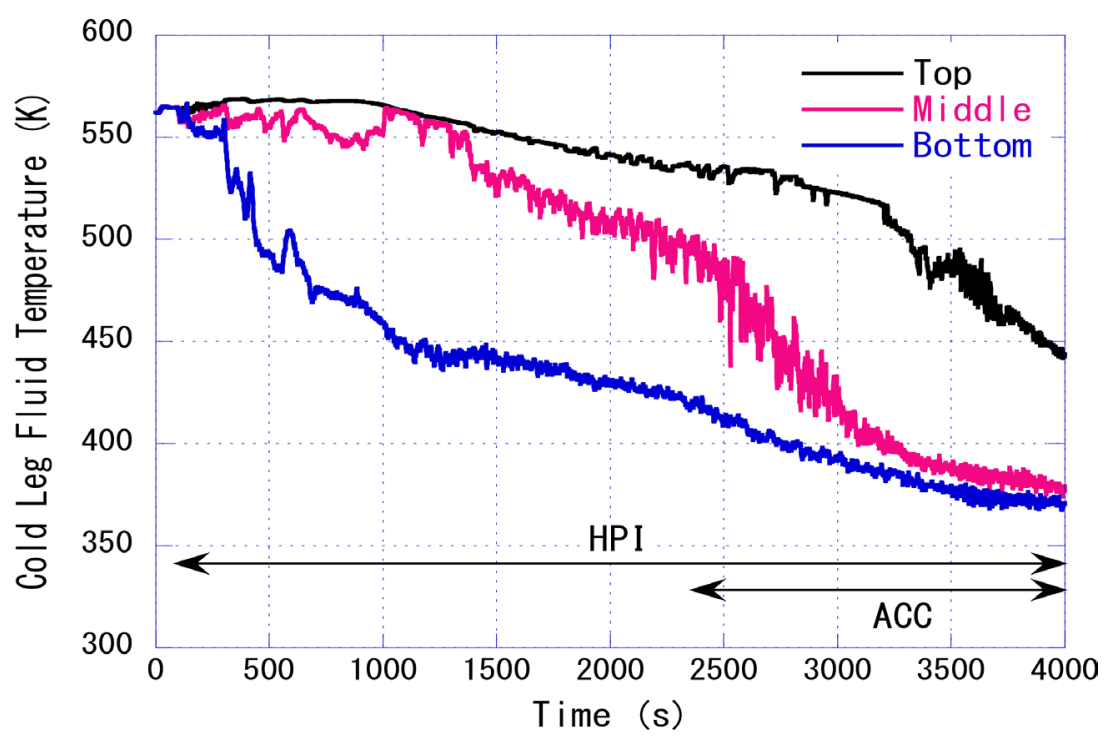

Figure 12. Cold leg fluid temperature in broken loop in SB-HL-17 test (LOCA with 1\% break at hot leg under single failure of HPI).

\subsubsection{Future Plan}

Additional investigation is necessary to better comprehend thermal stratification by means of IET on the small-break LOCA with thermal stratification under cold water injection from ECCS into cold legs. The IET is aimed at making clear the impacts of experimental parameters (break location and size, ECCS flow rate, ECCS injection temperature, etc.) on thermal stratification. The break location and size are supposed to be different from those in the SB-HL-17 test. The ECCS flow rate depends on the failure assumption. Mitigation means to raise the ECCS water temperature would reduce the failure probability of pressure vessel [47]. The injection temperatures of the HPI and ACC systems are expected to be different from those in the SB-HL-17 test. The ECCS injection temperatures will be determined on the basis of the fact that the highest injection temperature among the previously LSTF IETs was $322 \mathrm{~K}$ [36].

\subsection{Wide Spectrum LOCA with Core Uncovery under Totally Failed HPI System}

\subsubsection{Outline of the Event}

When LOCAs happen under totally failed HPI system, size of break has large effects on primary depressurization rate, and time to the core uncovery and the ACC system activation. There have been many IETs simulating LOCAs with a wide range of break sizes on the assumption of unavailability of the HPI system by using the LSTF. A test denoted as IB-CL-01 was the IET on the LOCA with the largest break size where the core was uncovered, while a test designated as SB-PV-08 was the IET on the LOCA with the smallest break size in combination with the AM action built on the CET performance.

\subsubsection{Major Conditions of Relevant LSTF Tests}

The IB-CL-01 test simulated a LOCA with $20 \%$ break at a cold leg in 2009. On 
the other hand, the scenario of the SB-PV-08 test was a LOCA with $0.1 \%$ break at vessel upper head supposing influx of nitrogen gas to the primary system in 2005. The SG RVs fully opening was undertaken as the AM measure in the case that the maximum CET raised to $623 \mathrm{~K}$. The SG secondary-side collapsed liquid level was maintained at around the initial liquid level via the AFW system operation during almost the whole transient. The common test condition assumed was that the HPI system was totally failed.

\subsubsection{Major Results of Relevant LSTF Tests}

In the IB-CL-01 test, medium size of break led to a fast depressurization in the primary system, as shown in Figure 13. Prior to loop seal clearing in both loops, the core dried out because of a quick depression in the core collapsed liquid lev$\mathrm{el}$, as depicted in Figure 14. The minimum collapsed liquid level of the core was close to the core bottom with relatively high core power. The maximum cladding surface temperature was higher than the criterion of $958 \mathrm{~K}$, which induced an automatic core power reduction to a certain low level. The PCT of $989 \mathrm{~K}$ was observed at Position 5 which is placed at a level of about $1 / 2$ of the active core height. The core collapsed liquid level restored with increasing the ACC flow rate (Figure 13).

In the SB-PV-08 test, by contrast, the primary pressure became slightly higher than the SG secondary-side pressure for a rather long time until the AM measure initiated, as presented in Figure 15. The upper plenum became voided being followed by a steep drop in the core collapsed liquid level, as described in Figure 16. Owing to the ACC water injection with quite low core power, the PCT of 697 $\mathrm{K}$ was seen at Position 7 and the entire core was quenched. Since nitrogen gas entered the primary loops and was conveyed to the SG U-tubes, a marked difference resulted between pressures on the primary and SG secondary sides (Figure 15).

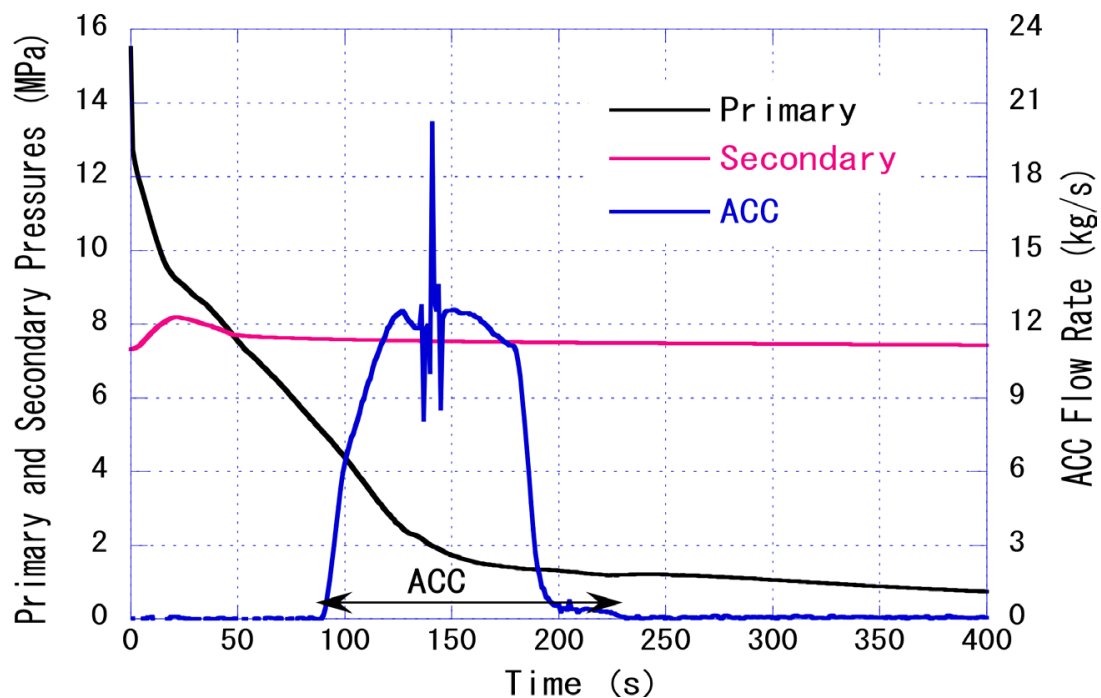

Figure 13. Primary and secondary pressures, and ACC flow rate in intact loop in IB-CL-01 test (LOCA with 20\% break at cold leg under no HPI). 


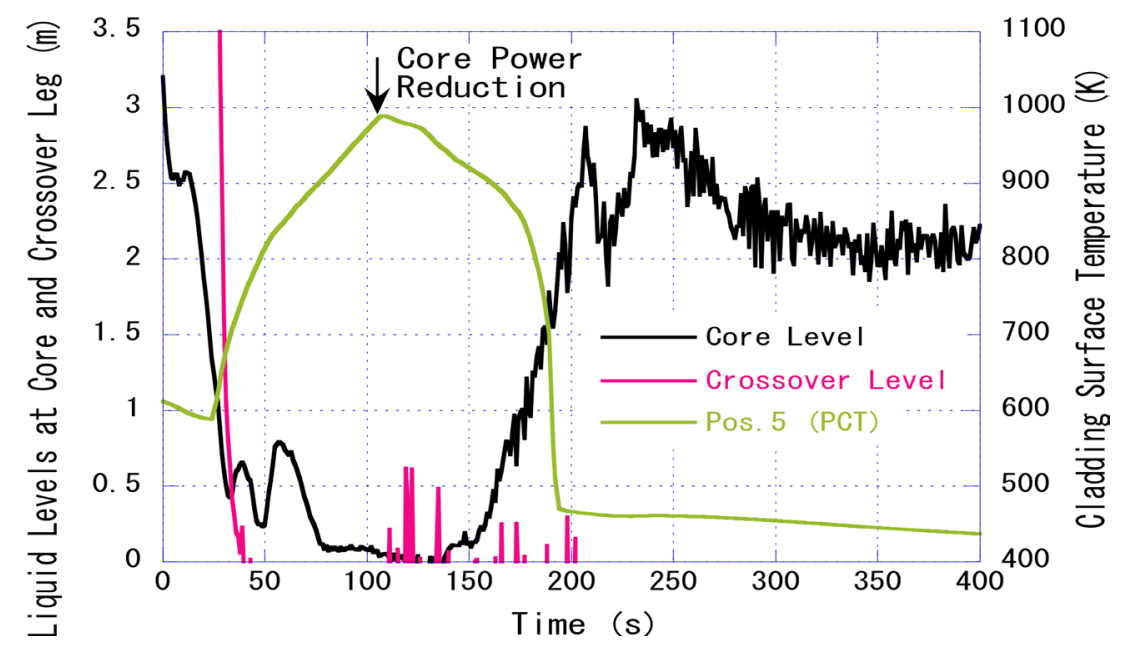

Figure 14. Collapsed liquid levels at core and crossover leg downflow-side in intact loop, and cladding surface temperature in IB-CL-01 test (LOCA with $20 \%$ break at cold leg under no HPI).

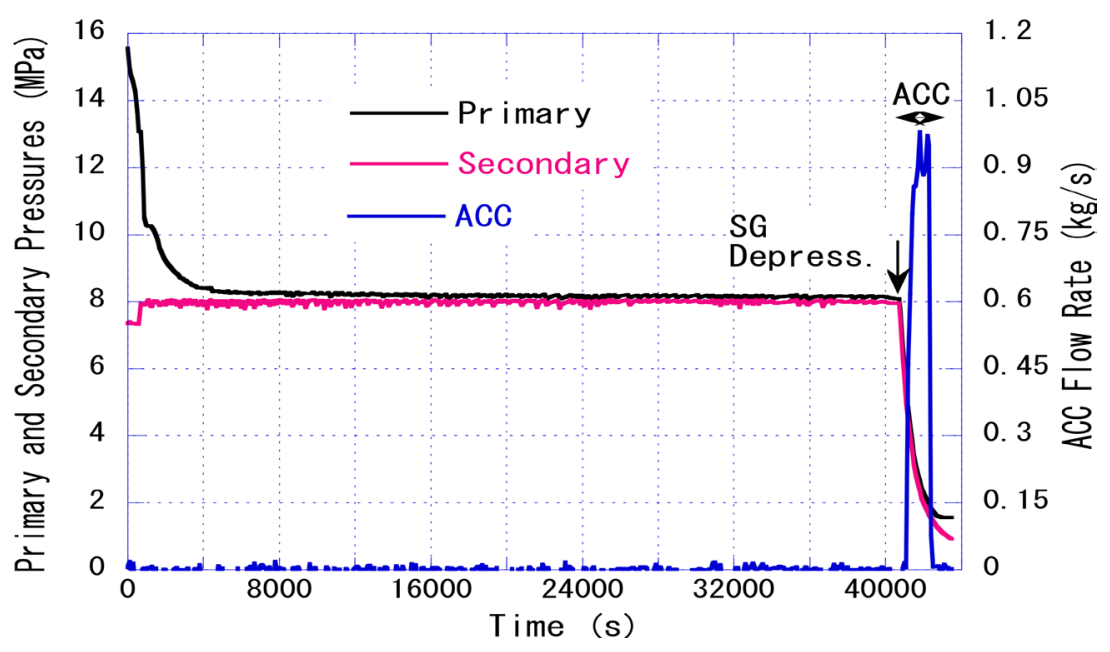

Figure 15. Primary and secondary pressures, and ACC flow rate in loop with PZR in SB-PV-08 test (LOCA with $0.1 \%$ break at vessel upper head with AM measures under no HPI).

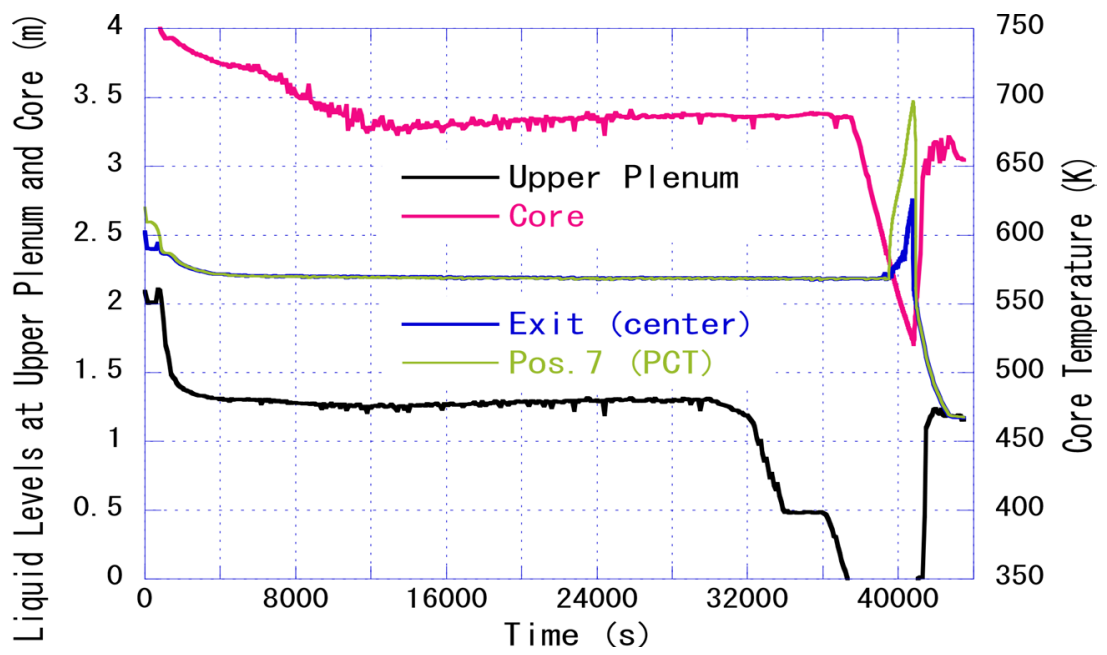

Figure 16. Core collapsed liquid level and core temperatures in SB-PV-08 test (LOCA with 0.1\% break at vessel upper head with AM measures under no HPI). 


\subsection{Anticipated Transient without Scram (ATWS) Following Small-Break LOCA under Totally Failed HPI System}

\subsubsection{Outline of the Event}

When scram failure assumes during a small-break LOCA with total-failure of the HPI system, the core power is relatively high. Core cooling performance would degrade as the primary coolant mass inventory reduces depending on a size of break. Break size of a test denoted as SB-CL-37 was the largest, while that of a test designated as SB-CL-36 was the smallest among relevant series IETs by use of the LSTF.

\subsubsection{Major Conditions of Relevant LSTF Tests}

The cold leg break sizes were $1.9 \%$ and $0.5 \%$ for the SB-CL-37 test and the SB-CL-36 test respectively in 2006. The HPI system was supposed to be unavailable as the common test condition. For each LSTF test, the core power curve was predetermined on the basis of the PWR calculation for the ATWS with the small-break LOCA utilizing the SKETCH-INS/TRAC-PF1 code [48]. Following a scram signal generation the AFW was injected into the SG secondary-side to restore the SG secondary-side collapsed liquid level.

\subsubsection{Major Results of Relevant LSTF Tests}

The pressure and core power transients and the liquid level transients respectively are indicated in Figure 17 and Figure 18 for the SB-CL-37 test, while those are presented in Figure 19 and Figure 20 for the SB-CL-36 test. The SG secondary-side pressure continued to increase on account of relatively high core power even after the SG RVs initiated cyclic opening (Figure 17 and Figure 19). The SG secondary-side pressure rose to about $8.6 \mathrm{MPa}$ in the SB-CL-37 test, whereas it raised to about $8.7 \mathrm{MPa}$ causing cyclic opening of safety valves in both

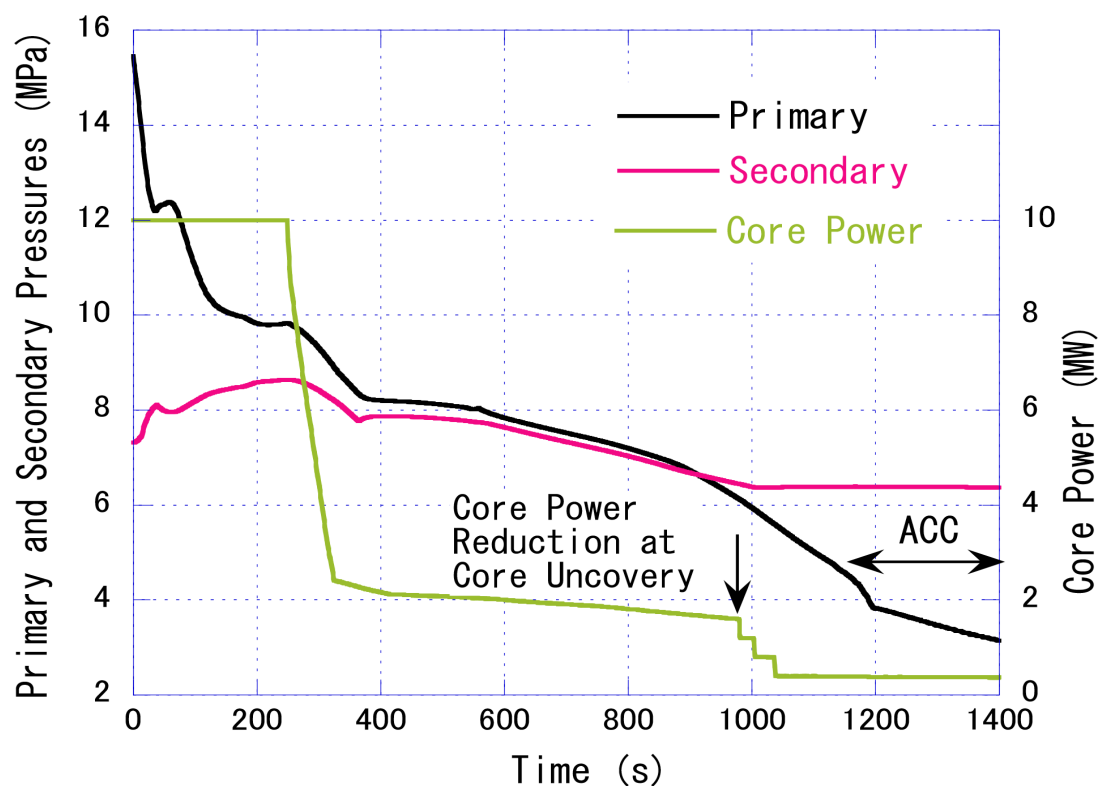

Figure 17. Primary and secondary pressures in intact loop, and core power in SB-CL-37 test (ATWS with $1.9 \%$ break at cold leg under no HPI). 


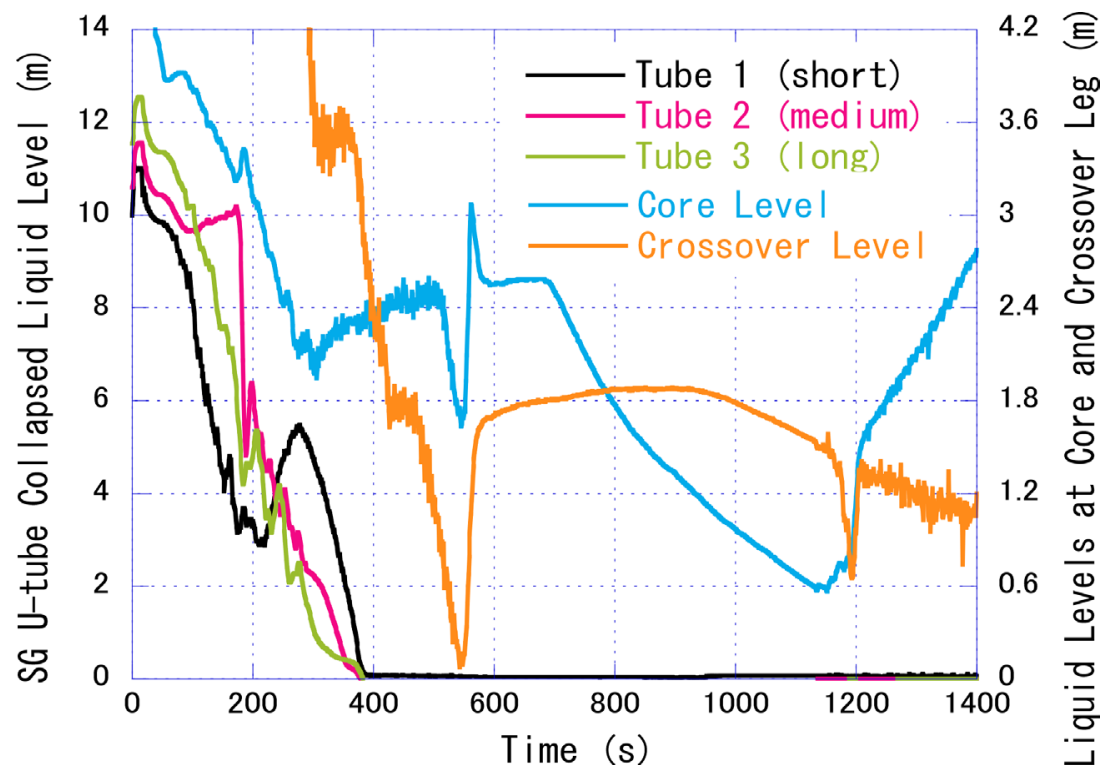

Figure 18. Collapsed liquid levels at SG U-tube upflow-side, core, and crossover leg downflow-side in intact loop in SB-CL-37 test (ATWS with LOCA with $1.9 \%$ break at cold leg under no HPI).

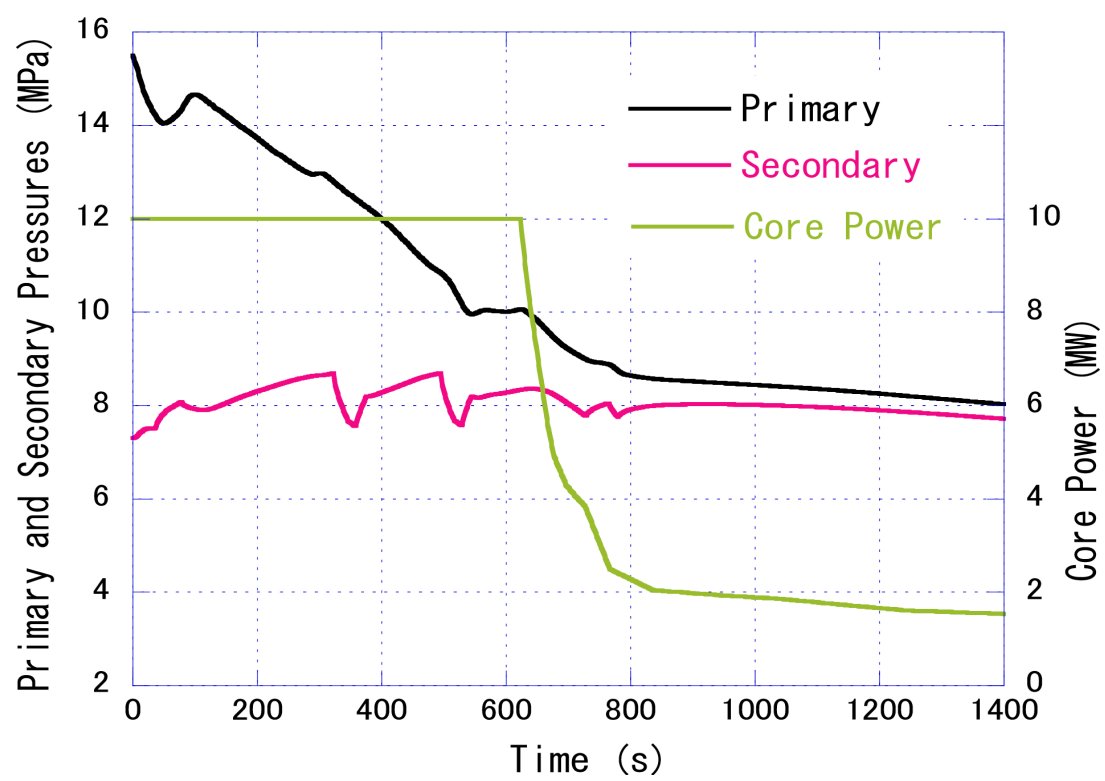

Figure 19. Primary and secondary pressures in intact loop, and core power in SB-CL-36 test (ATWS with LOCA with $0.5 \%$ break at cold leg under no HPI).

SGs in the SB-CL-36 test. The cyclic opening of the SG RVs ceased a little after the core power began to decline from the maximum value of $10 \mathrm{MW}$. Oscillative behavior of and temporary accumulation of coolant appeared at the upflow-side of the SG U-tubes (Figure 18 and Figure 20). Oscillative but small drop in the core collapsed liquid level resulted from the liquid holdup in the SG U-tube upflow-side.

In the SB-CL-37 test, the collapsed liquid level recovered in the core after loop seal clearing in both loops at the time of the first core uncovery. During the 


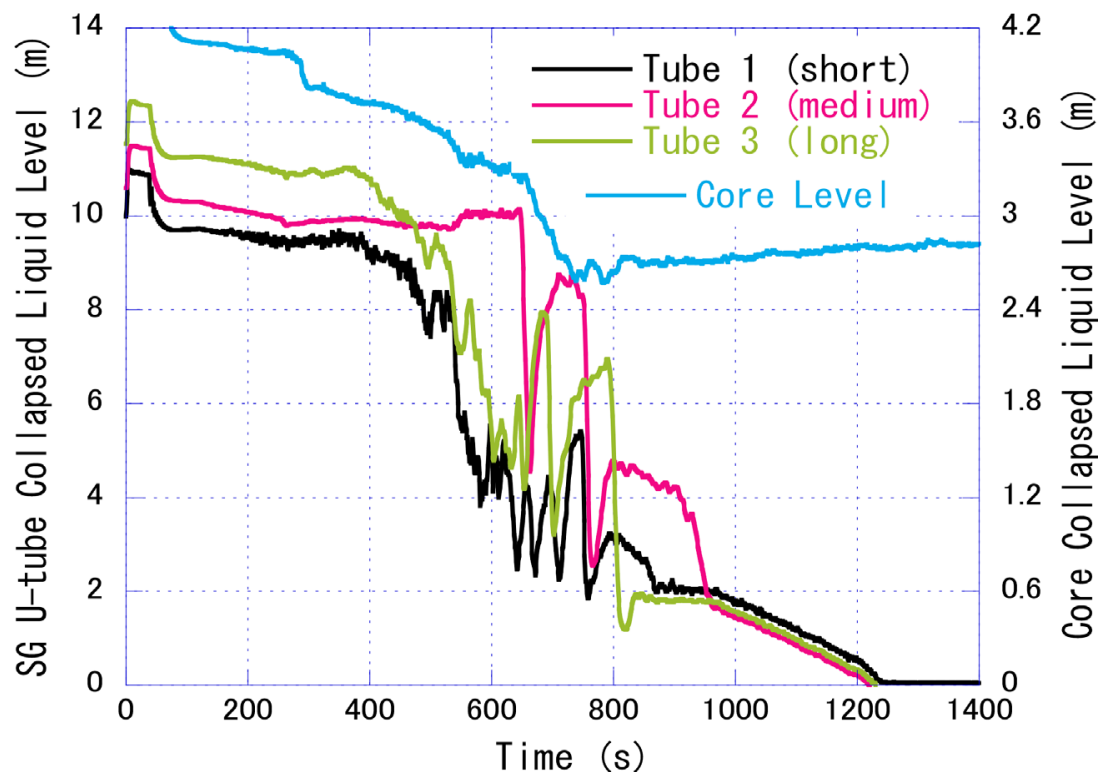

Figure 20. Collapsed liquid levels at SG U-tube upflow-side in intact loop and core in SB-CL-36 test (ATWS with LOCA with $0.5 \%$ break at cold leg under no HPI).

second core uncovery period, the core power was automatically decreased to a definite low level to avoid significant excursion of core temperatures. Steam condensation on the ACC water in both cold legs enhanced core reflooding afterwards. In the SB-CL-36 test, by contrast, the core collapsed liquid level remained by about $5 / 7$ of the active core height thereby producing no increase in the cladding surface temperature.

\section{Conclusions}

Regarding the new regulatory requirements for the Japanese light-water nuclear power plants, the review of the major outcomes of the relevant LSTF IETs resulted in the experimental identification of the thermal-hydraulic phenomena involved. The identified phenomena had great impacts on the parameters essential for the thermal-hydraulic safety assessment (e.g. primary pressure, core collapsed liquid level, and cladding surface temperature).

Recently, a series of IETs by use of the LSTF simulated MSGTR accident with recovery operation being coupled with severe multiple system failure. As the LSTF IET results, core uncovery would happen in the MSGTR accident under assumptions that the ECCS and the AFW system are completely failed resulting from loss of heat removal through the SGs.

Upcoming plans for the utilization of the LSTF are shown below. IET will be conducted to simulate the following PWR events; (a) total LOFW transient with the primary F \& B mode, (b) MSLB-induced MSGTR accident with the recovery action, (c) small-break LOCA with the AM measures on the CET reliability, and (d) small-break LOCA with thermal stratification under cold water injection from ECCS into cold legs. SET will be embarked at near-atmospheric pressure, concerning the loss of ECCS recirculation functions in a large-break LOCA. 
The LSTF experimental databases would be desirable for the following main subjects; (i) to cultivate better understanding of thermal-hydraulic phenomena and transient responses and (ii) to establish sophisticated measures and procedures for the PWR accidents and transients, and (iii) to further validate the predictive capabilities of best estimate system analysis codes for the underlying phenomena and computational fluid dynamics codes for the local multidimensional phenomena.

\section{Acknowledgements}

LSTF IETs denoted as TR-LF-16 on the SBO transient and designated as SB-SG16 , SB-SG-17, and SB-SG-18 on the recovery operation from the MSGTR accident were implemented under the auspices of Nuclear Regulation Authority, Japan.

\section{Conflicts of Interest}

The authors declare no conflicts of interest regarding the publication of this paper.

\section{References}

[1] The ROSA-IV Group (1985) ROSA-IV Large Scale Test Facility (LSTF) System Description. JAERI-M 84-237, Japan Atomic Energy Research Institute, Ibaraki.

[2] The ROSA-V Group (2003) ROSA-V Large Scale Test Facility (LSTF) System Description for the Third and Fourth Simulated Fuel Assemblies. JAERI-Tech 2003037, Japan Atomic Energy Research Institute, Ibaraki.

[3] Umminger, K., Dennhardt, L., Schollenberger, S. and Schoen, B. (2012) Integral Test Facility PKL: Experimental PWR Accident Investigation. Science and Technology of Nuclear Installations, 2012, Article ID: 891056. https://doi.org/10.1155/2012/891056

[4] Choi, K.Y., Kang, K.H. and Song, C.H. (2019) Recent Achievement and Future Prospects of the ATLAS Program. Nuclear Engineering and Design, 354, Article ID: 110168. https://doi.org/10.1016/j.nucengdes.2019.110168

[5] Kauppinen, O.P., Kouhia, V., Riikonen, V. and Hyvärinen, J. (2019) System Code Analysis of Accumulator Nitrogen Discharge during LOCA Experiment at PWR PACTEL Test Facility. Nuclear Engineering and Design, 353, Article ID: 110288. https://doi.org/10.1016/j.nucengdes.2019.110288

[6] Deng, C., Zhang, X., Yang, Y. and Yang, J. (2019) Research on Scaling Design and Applicability Evaluation of Integral Thermal-Hydraulic Test Facilities: A Review. Annals of Nuclear Energy, 131, 273-290. https://doi.org/10.1016/j.anucene.2019.03.042

[7] Kukita, Y., Anoda, Y. and Tasaka, K. (1991) Summary of ROSA-IV LSTF First-Phase Test Program-Integral Simulation of PWR Small-Break LOCAs and Transients. Nuclear Engineering and Design, 131, 101-111. https://doi.org/10.1016/0029-5493(91)90320-H

[8] Kukita, Y., Nakamura, H., Watanabe, T., Asaka, H., Yonomoto, T., Suzuki, M., Kumamaru, H. and Anoda, Y. (1992) OECD/NEA/CSNI International Standard Problem No.26 Comparison Report. NEA/CSNI/R(91)13. 
[9] Kukita, Y., Yonomoto, T., Asaka, H., Nakamura, H., Kumamaru, H., Anoda, Y., Boucher, T.J., Ortiz, M.G., Shaw, R.A. and Schultz, R.R. (1996) ROSA/AP600 Testing: Facility Modifications and Initial Test Results. Journal of Nuclear Science and Technology, 33, 259-265. https://doi.org/10.1080/18811248.1996.9731898

[10] Yonomoto, T., Kondo, M. and Kukita, Y. (1997) PWR Small Break Loss-of-CoolantAccident Experiment at ROSA-V/LSTF with a Combination of Secondary-Side Depressurization and Gravity-Driven Safety Injection. Journal of Nuclear Science and Technology, 34, 571-581. https://doi.org/10.1080/18811248.1997.9733710

[11] Asaka, H., Anoda, Y., Kukita, Y. and Ohtsu, I. (1998) Secondary-Side Depressurization during PWR Cold-Leg Small Break LOCAs Based on ROSA-V/LSTF Experiments and Analyses. Journal of Nuclear Science and Technology, 35, 905-915. https://doi.org/10.1080/18811248.1998.9733963

[12] Skorek, T., Krzykacz-Hausmann, B. and Austregesilo, H. (2011) Investigation of the Uncertainty of Governing Equation Systems in Thermalhydraulic Calculation. Proceedings of 14 th International Topical Meeting on Nuclear Reactor Thermal Hydraulics (NURETH-14), Toronto, Canada, 25-30 September 2011, Paper No: NURETH14-330, 1-12.

[13] Freixa, J. and Manera, A. (2012) Remarks on Consistent Development of Plant Nodalizations: An Example of Application to the ROSA Integral Test Facility. Science and Technology of Nuclear Installations, 2012, Article ID: 158617. https://doi.org/10.1155/2012/158617

[14] Mazgaj, P., Vacher, J.L. and Carnevali, S. (2016) Comparison of CATHARE Results with the Experimental Results of Cold Leg Intermediate Break LOCA Obtained during ROSA-2/LSTF Test 7. EPJ Nuclear Sciences \& Technologies, 2, 1-8. https://doi.org/10.1051/epjn/e2015-50020-7

[15] Takeda, T. and Ohtsu, I. (2017) RELAP5 Uncertainty Evaluation Using ROSA/LSTF Test Data on PWR 17\% Cold Leg Intermediate-Break LOCA with Single-Failure ECCS. Annals of Nuclear Energy, 109, 9-21. https://doi.org/10.1016/j.anucene.2017.05.007

[16] Nakamura, H., Watanabe, T., Takeda, T., Maruyama, Y. and Suzuki, M. (2009) Overview of Recent Efforts through ROSA/LSTF Experiments. Nuclear Engineering and Technology, 41, 753-764. https://doi.org/10.5516/NET.2009.41.6.753

[17] Nakamura, H., Takeda, T., Satou, A., Ishigaki, M., Abe, S. and Irwanto, D. (2013) Major Outcomes from OECD/NEA ROSA and ROSA-2 Projects. Proceedings of 15 th International Topical Meeting on Nuclear Reactor Thermal Hydraulics (NURETH-15), Pisa, 12-17 May 2013, Paper No: NURETH15-617, 1-21.

[18] NEA (2013) Final Integration Report of OECD/NEA ROSA Project 2005-2009. NEA/CSNI/R(2013)1.

[19] NEA (2017) Final Integration Report of Rig-of-Safety Assessment (ROSA-2) Project2009-2012. NEA/CSNI/R(2016)10.

[20] Choi, K.Y., Kim, Y.S., Song, C.H. and Baek, W.P. (2012) Major Achievements and Prospect of the ATLAS Integral Effect Tests. Science and Technology of Nuclear Installations, 2012, Article ID: 375070. https://doi.org/10.1155/2012/375070

[21] Takeda, T. and Ohtsu, I. (2017) ROSA/LSTF Test and RELAP5 Analyses on PWR Cold Leg Small-Break LOCA with Accident Management Measure and PKL Counterpart Test. Nuclear Engineering and Technology, 49, 928-940. https://doi.org/10.1016/j.net.2017.03.004

[22] Takeda, T. and Ohtsu, I. (2018) Uncertainty Analysis of ROSA/LSTF Test by RELAP5 Code and PKL Counterpart Test Concerning PWR Hot Leg Break LOCAs. 
Nuclear Engineering and Technology, 50, 829-841. https://doi.org/10.1016/j.net.2018.05.005

[23] Takeda, T. (2018) ROSA/LSTF Test and RELAP5 Code Analyses on PWR Hot Leg Small-Break LOCA with Accident Management Measure Based on Core Exit Temperature and PKL Counterpart Test. Annals of Nuclear Energy, 121, 594-606. https://doi.org/10.1016/j.anucene.2018.08.023

[24] NEA (2020) NEA Annual Report 2019. NEA No. 7517.

[25] Lorduy-Alós, M., Gallardo, S. and Verdú, G. (2020) Scaling Analysis of an IBLOCA Counterpart Test between the ATLAS and LSTF Facilities. Progress in Nuclear Energy, 127, Article ID: 103460. https://doi.org/10.1016/j.pnucene.2020.103460

[26] Bestion, D., D’Auria, F., Lien, P. and Nakamura, H. (2017) A State-of-the-Art Report on Scaling in System Thermal-Hydraulics Applications to Nuclear Reactor Safety. NEA/CSNI/R(2016)14.

[27] NRA (2014) FY2013 Nuclear Regulation Authority Annual Report. NRA, Tokyo.

[28] NRA (2014) Analyses of Events for the Evaluation of the Effectiveness of Measures against Severe Core Damage (PWR). NRA Technical Report Series, NTEC-2014-1001, Tokyo. (In Japanese)

[29] MacDonald, P.E., Shah, V.N., Ward, L.W. and Ellison, P.G. (1996) Steam Generator Tube Failures. NUREG/CR-6635 (INEL-95/0383), Idaho National Engineering Laboratory. https://doi.org/10.2172/236258

[30] NEA (2010) Core Exit Temperature (CET) Effectiveness in Accident Management of Nuclear Power Reactor. NEA/CSNI/R(2010)9.

[31] Lele, H.G., Gupta, S.K., Kushwaha, H.S. and Venkat Raj, V. (2002) Modelling of Thermal and Flow Stratification for Reactor Pressure Vessel Pressurised Thermal Shock. Nuclear Engineering and Design, 212, 75-84. https://doi.org/10.1016/S0029-5493(01)00485-X

[32] Lucas, D., Bestion, D., Bodèle, E., Coste, P., Scheuerer, M., D’Auria, F., Mazzini, D., Smith, B., Tiselj, I., Martin, A., Lakehal, D., Seynhaeve, J.M., Kyrki-Rajamäki, R., Ilvonen, M. and Macek, J. (2009) An Overview of the Pressurized Thermal Shock Issue in the Context of the NURESIM Project. Science and Technology of Nuclear Installations, 2009, Article ID: 583259. https://doi.org/10.1155/2009/583259

[33] Takeda, T. and Ohtsu, I. (2018) ROSA/LSTF Tests and Posttest Analyses by RELAP5 Code for Accident Management Measures during PWR Station Blackout Transient with Loss of Primary Coolant and Gas Inflow. Science and Technology of Nuclear Installations, 2018, Article ID: 7635878. https://doi.org/10.1155/2018/7635878

[34] Takeda, T., Asaka, H. and Nakamura, H. (2012) RELAP5 analysis of OECD/NEA ROSA Project Experiment Simulating a PWR Loss-of-Feedwater Transient with High-Power Natural Circulation. Science and Technology of Nuclear Installations, 2012, Article ID: 957285. https://doi.org/10.1155/2012/957285

[35] Yoshida, Y. (2020) Risk of Japanese PWR Plants by Shutting off Forced Core Cooling in an Accident Requiring Safety Injection System. Nuclear Engineering and Design, 368, Article ID: 110822. https://doi.org/10.1016/j.nucengdes.2020.110822

[36] Takeda, T., Ohnuki, A. and Nishi, H. (2015) RELAP5 Code Study of ROSA/LSTF Experiments on PWR Safety System Using Steam Generator Secondary-Side Depressurization. Journal of Energy and Power Engineering, 9, 426-442. https://doi.org/10.17265/1934-8975/2015.05.002

[37] Takeda, T. (2016) Data Report of ROSA/LSTF Experiment TR-LF-07; Loss-of-feedwater Transient with Primary Feed-and-Bleed Operation. JAEA-Data/Code 2016004, Japan Atomic Energy Agency, Ibaraki. 
[38] Murao, Y., Akimoto, H., Sudoh, T. and Okubo, T. (1982) Experimental Study of System Behavior during Reflood Phase of PWR-LOCA Using CCTF. Journal of Nuclear Science and Technology, 19, 705-719. https://doi.org/10.1080/18811248.1982.9734205

[39] Frepoli, C. (2008) An Overview of Westinghouse Realistic Large Break LOCA Evaluation Model. Science and Technology of Nuclear Installations, 2008, Article ID: 498737. https://doi.org/10.1155/2008/498737

[40] Park, H.S., Choi, K.Y., Cho, S., Kang, K.H., Choi, N.H., Kim, Y.S. and Baek, W.P. (2010) Major Findings from LBLOCA Reflood Tests Using the ATLAS Facility. Nuclear Engineering and Design, 240, 3920-3929. https://doi.org/10.1016/j.nucengdes.2010.02.003

[41] Takeda, T., Ohtsu, I. and Nakamura, H. (2013) OECD/NEA ROSA Project Experiment on Steam Condensation in PWR Horizontal Legs during Large-Break LOCA. Journal of Energy and Power Engineering, 7, 1009-1022. https://doi.org/10.1115/ICONE20-POWER2012-54427

[42] Kondo, S. (1994) Lessons Learned for PSA from the SGTR Incident at Mihama, Unit 2, in 1991. Reliability Engineering \& System Safety, 45, 57-65.

https://doi.org/10.1016/0951-8320(94)90076-0

[43] Julin, A., Lehto, M., Dupuy, P., Georgescu, G., Lanore, J.M., Turner, S., Calle-Vives, P., Grady, A.M. and Phan, H. (2014) Insights from PSA Comparison in Evaluation of EPR Designs. Proceedings of 12 th International Conference on Probabilistic Safety Assessment and Management (PSAM 12), Honolulu, 22-27 June 2014, 1-14.

[44] Lee, H., Seong, H., Park, G., Kumamaru, H. and Kukita, Y. (1996) Analysis of ROSA-IV/LSTF 10\% Main Steam Line Break Test Run SB-SL-01 Using RELAP5/ MOD3. Proceedings of 4th International Conference on Nuclear Engineering (ICONE-4), New Orleans, 10-14 March 1996, 41-50.

[45] Takeda, T. (2018) Data Report of ROSA/LSTF Experiment SB-PV-07; 1\% Pressure Vessel Top Break LOCA with Accident Management Actions and Gas Inflow. JAEA-Data/Code 2018-003, Japan Atomic Energy Agency, Ibaraki.

[46] Munoz-Cobo, J.L., Romero, A. and Chiva, S. (2013) Analysis with TRACE Code of Rosa Test 1.2: Small LOCA in the Hot-Leg with HPI and Accumulator Actuation. International Agreement Report NUREG/IA-0420.

[47] Katsuyama, J., Masaki, K., Lu, K., Watanabe, T. and Li, Y. (2019) Effect of Coolant Water Temperature of ECCS on Failure Probability of RPV. Proceedings of ASME 2019 Pressure Vessels \& Piping Conference (PVP2019), San Antonio, 14-19 July 2019, Paper No: PVP2019-93967, V001T01A059. https://doi.org/10.1115/PVP2019-93967

[48] Zimin, V.G., Asaka, H., Anoda, Y. and Enomoto, M. (1999) Verification of J-TRAC Code with 3D Neutron Kinetics Model SKETCH-N for PWR Rod Ejection Analysis. Proceedings of the 9 th International Topical Meeting on Nuclear Reactor Thermal Hydraulics (NURETH-9), San Francisco, 3-8 October 1999, Paper No: Log241, $1-17$. 